This is a postprint version of the following published document:

Castronuovo, E. D.; Usaola, J.; Bessa, R.; Matos, M.; Costa, I. C.;

Bremermann, L.; Lugaro, J.; Kariniotakis, G. (2014). An integrated approach for optimal coordination of wind power and hydro pumping storage. Wind Energy, v. 17, Issue 6, pp. 829-852.

DOI: $10.1002 /$ we. 1600

(C) John Wiley \& Sons 2014 


\title{
An integrated approach for optimal coordination of wind power and hydro pumping storage
}

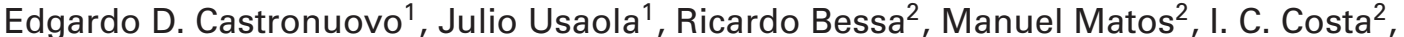 \\ L. Bremermann ${ }^{2}$, Jesus Lugaro ${ }^{3}$ and George Kariniotakis ${ }^{3}$ \\ 1 Department of Electrical Engineering, University Carlos III de Madrid, Av. De la Universidad 30, 28911 Leganés, Madrid, Spain \\ 2 INESC TEC_INESC Technology and Science (formerly INESC Porto) and FEUP_Faculty of Engineering, University of Porto, \\ Campus da FEUP, Rua Dr. Roberto Frias 378, 4200-465 Porto, Portugal \\ 3 PERSEE-Center for Processes, Renewable Energies \& Energy Systems, MINES ParisTech, Rue Claude Daunesse, F-06904 \\ Sophia Antipolis, France
}

\begin{abstract}
The increasing wind power penetration in power systems represents a techno-economic challenge for power producers and system operators. Because of the variability and uncertainty of wind power, system operators require new solutions to increase the controllability of wind farm output. On the other hand, producers that include wind farms in their portfolio need to find new ways to boost their profits in electricity markets. This can be done by optimizing the combination of wind farms and storage so as to make larger profits when selling power (trading) and reduce penalties from imbalances in the operation. The present work describes a new integrated approach for analysing wind-storage solutions that make use of probabilistic forecasts and optimization techniques to aid decision making on operating such systems. The approach includes a set of three complementary functions suitable for use in current systems. A real-life system is studied, comprising two wind farms and a large hydro station with pumping capacity. Economic profits and better operational features can be obtained from the proposed cooperation between the wind farms and storage. The revenues are function of the type of hydro storage used and the market characteristics, and several options are compared in this study. The results show that the use of a storage device can lead to a significant increase in revenue, up to $11 \%$ (2010 data, Iberian market). Also, the coordinated action improves the operational features of the integrated system. Copyright (C) 2013 John Wiley \& Sons, Ltd.
\end{abstract}

\section{KEYWORDS}

wind power; generation dispatch; pumped storage; hydro generation; deterministic; probabilistic; uncertainty; decision making; optimization

\section{Correspondence}

Edgardo D. Castronuovo, Department of Electrical Engineering, University Carlos III de Madrid, Av. De la Universidad 30,

28911 Leganés, Madrid, Spain.

E-mail: ecastron@ing.uc3m.es

\section{NOMENCLATURE}

$C_{\mathrm{ESS} i} \quad$ forecasted storage cost at interval $i$ during the intraday optimization

$c_{\text {hydro }}$

$C_{\mathrm{IMB} i}$

$c_{\text {pump }}$

$E_{i}$

$E_{i}^{*}$

$E^{M}$

$E^{R}$

$E_{r}^{\text {begin }}$

$E_{r}^{\text {end }}$ cost for producing energy from stored energy

forecasted imbalance cost at interval $i$ during the intraday optimization

cost of pumping

amount of energy that is stored in the reservoir in period $i$

amount of energy scheduled to remain in the reservoir at period $i$ during the intraday optimization

maximum storage capacity of the reversible hydro station

energy margin to be maintained in each period

initial amount of the residual hydro storage availability in the reservoir for the next day

value of the desired remaining storage availability at the end of the optimization 


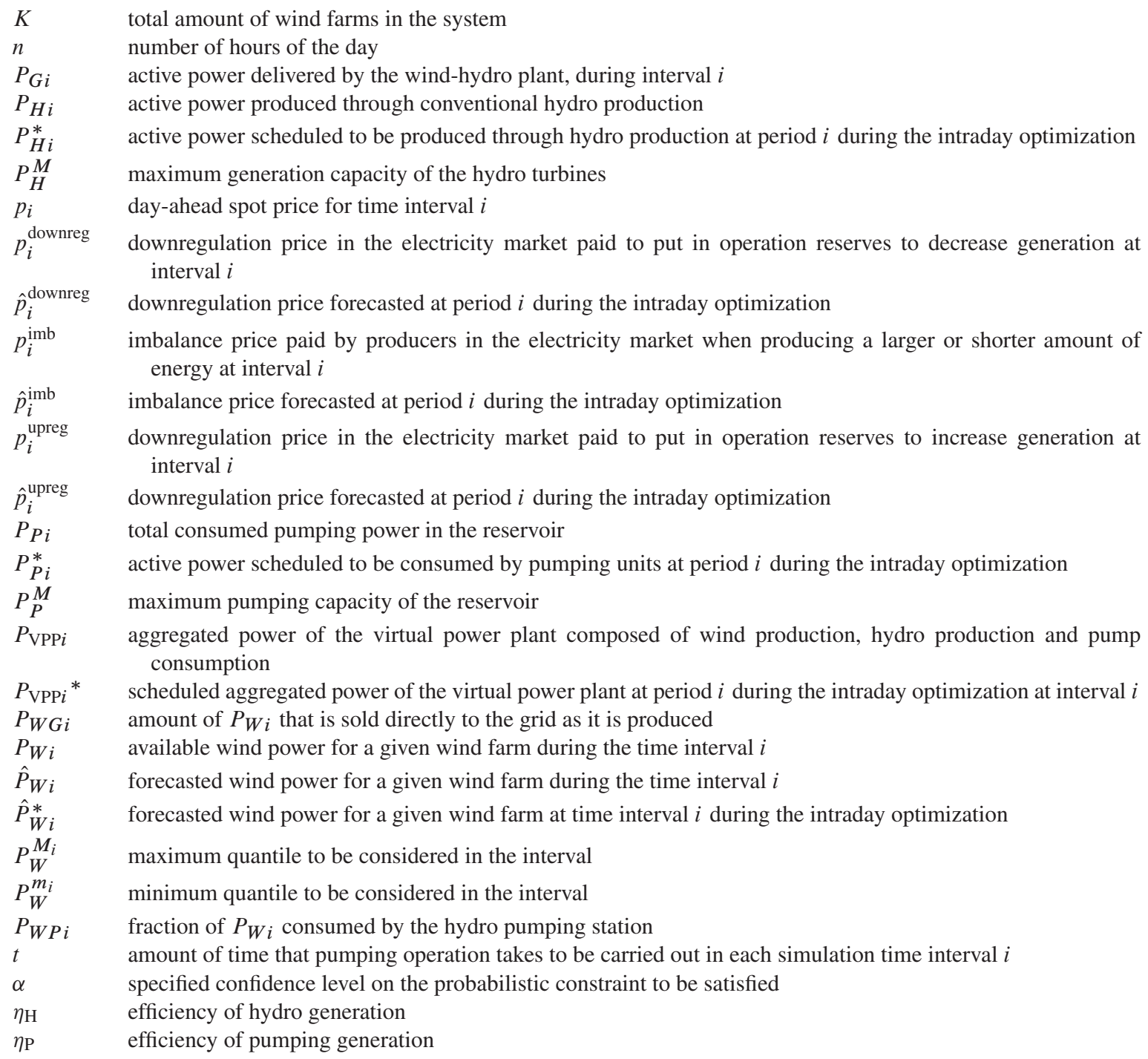

\section{INTRODUCTION}

The increased penetration of wind energy in power systems has led to the development of new operational procedures. To improve the output characteristics of the wind farms, one of the methods most frequently used in literature is to coordinate them with storage devices, to compensate the expected production deviations of wind power generation. Wind power adds excellent properties to the power generation mix because of reduced $\mathrm{CO}_{2}$ emissions, local availability, lower dependence on foreign energy sources, and utilization of energy resources periodically restored to the original state for the nature, among others. However, in wind power, it is impossible to predict a plant's real-time behavior at any moment in the future because of the limited control abilities of wind farms and the variability of the energy resource. As wind cannot be stored directly, the variation between the power injected into the system and the previously scheduled one (due to errors in the production forecast) must be compensated by other generators to maintain the balance between generation, load and losses. ${ }^{1,2}$ Alternatively, wind farm production can be combined with storage devices, with the result that power generation can be modulated as desired.

Several proposals have been made to analyse the cooperation between wind farms and storage plants. Castronuovo and Peças Lopes ${ }^{3}$ proposed the collaboration between a wind farm and a water pump station to reduce the economic losses caused by operational restrictions. The main motivation behind this study is to use a hydro storage facility to increase the wind farm's controllability and additionally to maximize profits. Matevosyan and Söder ${ }^{4}$ consider the cooperation between a wind farm and a conventional multi-reservoir hydropower system, in a 1 year horizon. The coordination between the hydropower producer and the wind farm decreases the wind energy curtailments, solving the congestion restriction with 
an efficient approach. Matevosyan et al. ${ }^{5}$ also consider the day-ahead planning algorithm for a multi-reservoir hydropower system coordinated with wind power in northern Sweden. Garcia-Gonzalez et al. ${ }^{6}$ analyse the combined operation of wind farms and a pump hydro facility, considering the uncertainties in both wind power generation and market prices. The models developed could be used as approaches to assist optimal production management.

The optimal sizing for the adequate interrelation between the wind farm and the storage devices is also considered in the literature. In Castronuovo and Peças Lopes, ${ }^{7}$ the optimal sizes of the wind farm and some elements of the water pump station are calculated. Anagnostopoulos and Papantonis ${ }^{8}$ also consider the optimum sizing and design of a pump station unit for combined operation with a wind farm. The work aims to find the optimal 'Net Present Value' for the investment in a 1 year simulation by varying the number of pumps used in the station. The results show the importance of using variablespeed pump units. Abbey and $\operatorname{Joos}^{9}$ develop a method to optimize the storage sizing for remote communities with wind and diesel generation. The results show that the availability of storage, together with an appropriate diesel operating approach, can result in significant cost savings in terms of fuel and operations. Brown et al. ${ }^{10}$ show that pumped storage can be very useful in isolated systems, improving both the dynamic security and the economic operation of the grid. Kockl et al. ${ }^{11}$ discuss several technological aspects of energy storage devices where storage is used to filter the erratic power output of a stochastic power source (e.g. wind power generator). Vieira and Ramos ${ }^{12}$ use a pump hydro storage device to calculate the optimal operation of a system in Portugal's Madeira Island, with hydro and wind power generation in the system.

The significant influence of the market conditions for the combined operation is studied in many works. In particular, Korpaas et al. ${ }^{13}$ propose a method for scheduling and operating an energy storage system coupled with a wind power plant under market conditions. The method considers constant wind power forecasts throughout the scheduling period and requires a precise knowledge of future market prices. Koeppel and Korpås ${ }^{14}$ analyse the use of a generic energy storage device for balancing the differences between forecasted and real productions in a wind farm, when acting in a market environment. The proposed algorithm uses the forecasted values of wind production to evaluate the best storage operation,

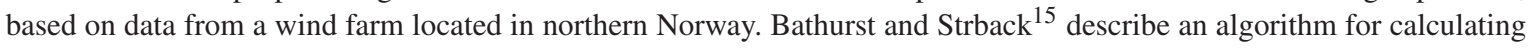
the optimal short-term dispatch of an energy storage facility coupled with a wind farm, aiming at minimizing the expected imbalance penalties incurred by the wind farm owner. Martínez-Crespo et al. ${ }^{16}$ analyse some approaches to effectively integrating large amounts of wind energy into the system, including the use of storage devices. Angarita et al. ${ }^{17}$ propose two methods for minimizing penalties incurred by imbalances in a wind farm's power output. The first of these methods considers a wind farm bidding alone in the day-ahead market and attempts to minimize the risk of the bid based on a statistical analysis of the expected production probability. The second one couples a hydro power plant containing a water reservoir with the wind farm so as to minimize the imbalance costs incurred by the wind farm owner.

The previous studies have investigated the collaborations of hydro-wind as individual parts but not as a whole. The present work describes a new tool that integrates three new functions for the analysis of wind-storage solutions in dayahead markets: (i) optimal hydro-wind coordination to maximize market profit; (ii) optimal scheduling of a large storage device to compensate wind power deviations; and (iii) management of storage coupled with wind farms to minimize imbalance costs in the market. The functions can be used in integrated or independent ways and cover most of the objectives analysed in the literature cited. The implemented functions can be used by operators, producers and traders to improve the operation of their systems, adapted to the particular characteristics of each problem. The tool makes use of probabilistic forecasts to aid decision making on operating such systems. The functions have also been implemented into a platform developed in the framework of the European Project ANEMOS.plus. ${ }^{18}$

The paper is structured as follows. In Section 2, some relevant aspects associated with wind power forecasting, and in particular probabilistic forecasting, are reviewed. In Sections 3-5, the three functions are fully described. The results from a real-life case study (comprising two wind farms and a large hydrostation with pumping units in the Iberian Peninsula) illustrate the efficiency of the cooperation between wind power and storage, in Section 6. Finally, Section 7 includes the conclusions of the analysis.

\section{WIND POWER FORECASTS}

The functions developed in this paper plan the hydro-wind optimized strategy for the next day, and this requires wind power forecasts covering the day ahead. Many methods have been developed with this objective in the European Project ANEMOS. ${ }^{19}$ A state of the art in wind power forecasting models can be found in Giebel et al. ${ }^{20}$ The forecasting approaches available in the ANEMOS platform can be considered as the current state of the art in wind power forecasting. The platform is used for online operations in several European System Operators and utilities, and other companies in the energy sector can request interconnection with the platform.

Point forecasts consist of single power values provided for each time step in the future. Point forecasts are normally calculated through a physical approach, a statistical approach or a combination, all using weather forecast data as input. Probabilistic forecasts provide uncertainty information for each single time step in the future. A commonly used representation of uncertainty information ${ }^{21}$ is through non-parametric probabilistic predictions, such as quantiles, ${ }^{22}$ intervals, ${ }^{23}$ probability density functions ${ }^{24}$ and scenarios incorporating a temporal interdependence structure of prediction errors. ${ }^{25}$ 
In the demonstration case studied in this paper, a statistical forecasting approach from the ANEMOS platform was used to provide point forecasts. Then for providing information about the likelihood of forecast errors, an uncertainty module was used to provide probabilistic forecasts. These probabilistic forecasts are provided in the form of quantiles, ranging between $5 \%$ and $95 \%$ with $5 \%$ increments.

In the following sections, a description of each of the three implemented functions is given.

\section{FUNCTION A: HYDRO-WIND COORDINATION TO MAXIMIZE THE DAY-AHEAD MARKET PROFIT}

In this section, an hourly discretized optimization algorithm is presented, which makes it possible to identify the optimum daily operational strategy to be followed by both wind farms and a hydro generation pumping unit, using the hourly wind power forecast produced by the ANEMOS platform. The optimization of the resulting wind-hydro power system allows wind farm operators to improve the daily economic operational profit. The uncertainty of wind power forecasting is taken into account through a chance-constrained algorithm (i.e., risk-based decision) that allows the decision maker to choose the operating strategy that corresponds to the level of risk that he or she is prepared to accept. The approach presented in this section extends the previous work in Castronuovo and Peças Lopes, ${ }^{3}$ by including the operational strategy followed by the wind farm and wind power probabilistic forecasts.

\subsection{Day-ahead optimization}

Day-ahead optimization ${ }^{3}$ consists in taking advantage of the system's storage capability, by storing wind energy produced during low-price periods to sell at a later date, when the daily energy price rises.

The inputs of the day-ahead optimization are static data of the hydro power plant, wind power and spot price forecasts for the next day. On the basis of the input data, a linear programming algorithm is solved, providing the daily operational strategy to be followed in order to achieve the maximum revenue in the electricity market, transposed into a form of amount of wind that should be sold directly to the grid, amount to be used in pumping operation and amount of energy to be delivered by hydro generation during each hour.

Note that in this formulation, the deviation costs are not included in the objective function; this is addressed by Function $\mathrm{C}$ in Section 5. The problem is solved using an interior-point method, where wind power is presumed to be constant during each simulation period. This can be summarized by the following optimization problem:

$$
\begin{gathered}
\operatorname{Max} \sum_{i=1}^{n}\left[p_{i} \cdot P_{G i}-c_{\text {pump }} \cdot P_{W P i}-c_{\text {hydro }} \cdot P_{H i}\right] \\
\text { s.t. } \quad P_{G i}=P_{W G i}+P_{H i} \\
P_{W i}=P_{W P i}+P_{W G i} \\
E_{i+1}=E_{i}+t \cdot\left[\eta_{p} \cdot P_{W P i}-\frac{P_{H i}}{\eta_{H}}\right] \\
0 \leq E_{i} \leq E^{M} \\
E_{1}=E_{r}^{\mathrm{begin}} \\
E_{24}=E_{r}^{\mathrm{end}} \\
0 \leq P_{H i} \leq P_{H}^{M} \\
P_{H i}=\sum_{H} \cdot\left[\frac{E_{i}}{t}+\eta_{p} \cdot P_{W P i} P_{W P i, k}\right. \\
0 \leq P_{P i} \leq P_{P}^{M} \\
P_{P i} \\
P_{H}
\end{gathered}
$$


where $p_{i}$ is the day-ahead spot price for time interval $i, n$ is the number of hours of the day, $P_{G i}$ is the active power delivered to the network by the wind-hydro plant, during interval $i, P_{W i}$ is the available wind power for a given wind farm during the time interval $i, P_{W P i}$ is the fraction consumed by the hydro pumping station, $P_{W G i}$ is the amount of $P_{W i}$ that is sold directly to the grid as it is produced, $c_{\text {pump }}$ is the cost of pumping, $c_{\text {hydro }}$ is the cost for producing energy from stored energy, $P_{H i}$ is the active power produced through conventional hydro production, and $E_{i}$ is the amount of energy that is stored in the reservoir in period $i$.

From the objective function of equation (1), one can identify three terms: the first aims to maximize the profit associated with the delivery of active wind power to the grid, the second incorporates hydro pumping cost into the profit calculation and the third integrates hydro generating cost into the optimization problem.

The algorithm considers $P_{G i}$, which represents the total amount of wind power effectively supplied to the grid, either by instantaneous system wind generation $P_{W G i}$ or using the hydro generation unit for supplying $P_{H i}$ during time interval $t$ from the energy previously stored in the hydro reservoirs, as indicated in (2).

The available wind power for a given wind farm during the time interval $i, P_{W i}$, is described by a vector containing the 24 values of the forecasted wind power availability for each hour. According to expression (3), in each time interval, $P_{W i}$ is divided into two different quantities: (i) the fraction consumed by the hydro pumping station, $P_{W P i}$, and (ii) the fraction delivered directly to the grid as it is produced, $P_{W G i}$. In each simulation period $i$, the amount of wind energy stored in the hydro pumping station, $E_{i}$, will be increased using hydro pumping capacity $\left(P_{W P i}\right)$. At the same time, the energy contained within the hydro reservoir can be decreased through conventional hydro production, $P_{H i}$ (equation (4)). During each time period, the maximum amount of energy that can be stored in the hydro reservoir cannot exceed the maximum available storage capacity $E^{M}$, corresponding to a given residual storage capacity in the reversible hydro station (equation (5)). $\eta_{\mathrm{P}}$ and $\eta_{\mathrm{H}}$ are the efficiencies of pumping and hydro generation, respectively; $t$ is the amount of time that pumping operation takes to be carried out in each simulation time interval $i$ (in the present formulation, $t=1 \mathrm{~h}$ ). The application of equation (4) requires an indication of the day-ahead amount of the residual hydro available storage capacity in the reservoir, $E_{r}^{\text {begin }}$. Regarding the oversight of the available hydro resources in the hydro pumping station, the value of the desired remaining storage availability at the end of the optimization, $E_{r}^{e n d}$, is also specified, in order to obtain a consistent planning scheme for the reservoir.

The maximum value that $P_{H i}$ can assume is limited by two main physical constraints: (i) the maximum generation capacity of the hydro turbines $P_{H}^{M}$ and (ii) the amount of water stored in the reservoir due to wind energy pumping during previous time periods. These restrictions are translated by equations (8) and (9).

In the reservoir, the total consumed pumping power $P_{P i, r}$ is assumed to be unvarying throughout each simulation period $i$. The value of $P_{P i, r}$ must equal the sum of the power contributions supplied by the $K$ wind farms, equation (10). The maximum value that $P_{P i}$ can assume is limited by the system's maximum pumping capacity, $P_{P}{ }^{M}$, according to equation (11).

\subsection{Operational strategy}

The selling bids must be submitted to the market pool in the day (day D) before to the operation (day D+1). This bid schedule is provided by the day-ahead optimization described in the previous section. Hence, the wind power producer needs to manage forecast deviations during the operating time to operate close to the optimal day-ahead strategy. Note that the revenue obtained with the day-ahead strategy is simply an extrapolation that assumes a perfect forecast. This means that to make a proper evaluation (i.e. computing the real revenue), operational strategies that take into account the day-ahead strategy need to be developed.

The merge of the day-ahead and operational strategies is explained in Figure 1. The basic idea is as follows: first, the day-ahead optimization computes the wind-hydro generation schedule on which the producer relies to submit the power bids to the market; then on the basis of the day-ahead bids, ratio coefficients are computed, such as the percentage of wind power delivered to the grid, $\hat{P}_{W G i} / \hat{P}_{W i}$, the percentage of wind power used in the pumping operation, $\hat{P}_{W P} / \hat{P}_{W i}$ and the percentage of power delivered to the grid during time interval $t$ by the hydro unit using the energy stored in the reservoirs, $\hat{P}_{H i} \cdot t / \hat{E}_{i}$, thus quantifying the day-ahead strategy; finally, during the operational settlement day, the same ratio coefficients are computed, but as a function of the realized wind power generation and stored energy.

Note that during the operational day, forecast errors will result in different values of wind power generation or pumped electrical energy. Therefore, an evaluation is carried out to ensure that technical constraints are not violated, and if they are, corrective actions, defined by standard procedures, are applied to solve them. For instance, if the maximum pumping capacity and/or storage level is exceeded as a consequence of the Operational Strategy, then in the operational scenario, the pumping capacity is set to the maximum capacity available or to the maximum capacity that the storage device can amass. The residual wind power is delivered directly to the grid, and if there is a bottleneck situation, this residual generation must be curtailed. If the hydro generation output is then exceeded, in the operational scenario, the hydro generation output is set to the maximum value available and the undelivered residual electrical energy remains available in the storage device for the next pumping periods. 


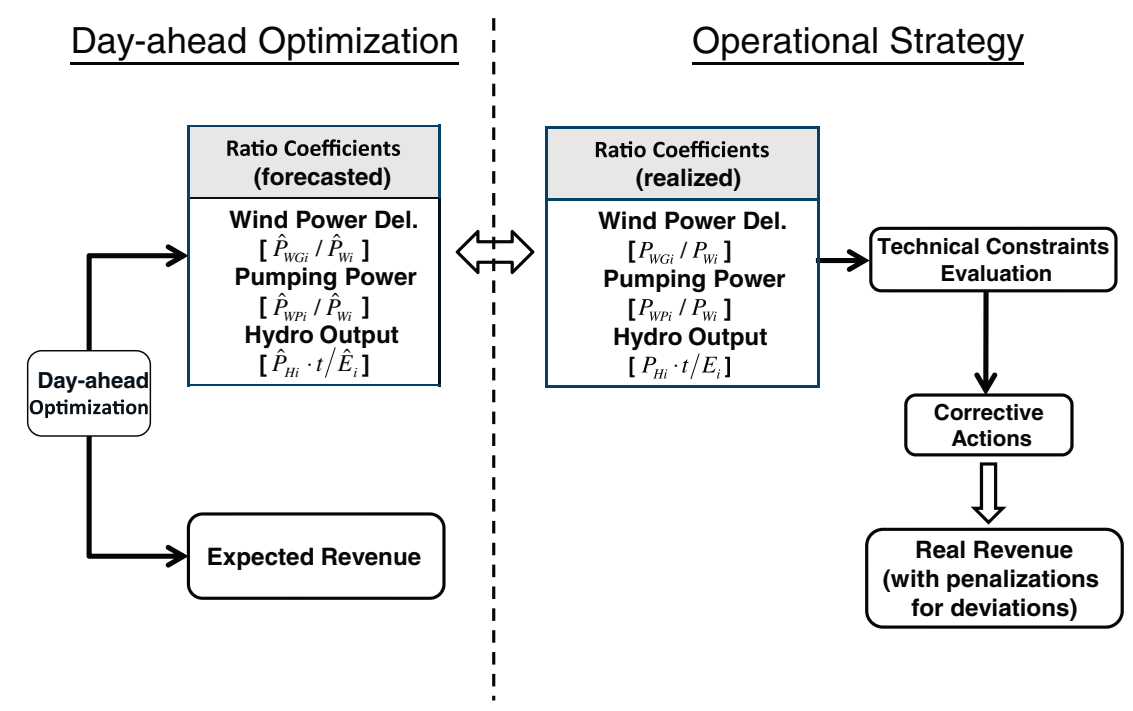

Figure 1. Day-ahead and operational strategies.

Finally, the real revenue is calculated, introducing the penalties incurred for deviations between the bid and the delivered value.

An example helps to illustrate the Operational Strategy concept. The wind power forecast predicts that during a specific hour, the available wind power, $\hat{P}_{W i}$, will be $100 \mathrm{MW}$. On the basis of this value and the remaining input data, the dayahead optimization computes the wind-hydro strategy to be followed, ascertaining that of the $100 \mathrm{MW}, 20 \mathrm{MW}$ should be delivered directly to the grid, $\hat{P}_{W G i}$, and the remaining $80 \mathrm{MW}$ should be used to pump water into the reservoirs. The day-ahead optimization also specifies that $50 \mathrm{MW}$ (i.e. value of $\mathrm{P}_{\mathrm{Hi}}$ ) should be delivered to the grid by hydro generation during $t$ (i.e. $1 \mathrm{~h}$ ), from the actual storage level, $\hat{E}_{i}$, which at this hour is $500 \mathrm{MWh}$ (for a maximum of $600 \mathrm{MWh}$ ). The ratio coefficients can now be calculated, resulting in $\hat{P}_{W G i} / \hat{P}_{W i}=20 \%, \hat{P}_{W P} / \hat{P}_{W i}=80 \%$, and $\hat{P}_{H i} \cdot t / \hat{E}_{i}=10 \%$. During the operation day, these ratios are now computed as a fraction of the realized values, so that if instead of the predicted $100 \mathrm{MW}$ of wind power the realized value is $200 \mathrm{MW}$, the producer will sell $20 \%$ of this value (40 MW) directly to grid, use $160 \mathrm{MW}$ to pump water to the reservoir and deliver $10 \%$ of the energy stored with the hydro plant (i.e. if the realized storage level in this hour is $300 \mathrm{MWh}$, the hydro delivers $30 \mathrm{MWh}$, or $30 \mathrm{MW}$ during $t$ ). In this example, if the pumping unit uses the $160 \mathrm{MW}$ for pumping water during $t$, this would violate the reservoir capacity limit; thus, to comply with this constraint, the following corrective action is taken: only $100 \mathrm{MW}$ are used for pumping water, and the remaining $60 \mathrm{MW}$ are delivered to the grid (in addition to the $40 \mathrm{MW}$ ). This strategy results in an hourly real output from the combined hydro-wind stations to be delivered to the grid, and the deviations will then be included in the revenue in the form of a penalty.

Note that during the operational day, forecast errors will result in different values of wind power generation or pumped electrical energy. Therefore, an evaluation is carried out to ensure that technical constraints are not violated, and if they are, corrective actions, defined by standard procedures, are applied to solve them. For instance, if the maximum pumping capacity and/or storage level exceeded as a consequence of the Operational Strategy, then in the operational scenario, the pumping capacity is set to the maximum capacity available, or to the maximum capacity that the storage device can amass. The residual wind power is delivered directly to the grid, and if there is a bottleneck situation, this residual generation must be curtailed. If the hydro generation output then exceeded, in the operational scenario, the hydro generation output is set to the maximum value available and the undelivered residual electrical energy remains available in the storage device for the next pumping periods.

\subsection{Chance-constrained Optimization}

To increase the robustness of the approach regarding wind power uncertainty, the deterministic algorithm presented so far was enhanced to accept probabilistic wind power forecasts. This approach places emphasis on risk-related aspects, allowing the decision maker to choose the level of risk he or she is prepared to accept and obtain the corresponding solution. This approach places emphasis on risk-related aspects. Naturally, more risky solutions will allow higher expected revenue, while more risk-adverse solutions will incur a drop in the expected revenue. It is up to the decision maker to evaluate the 
trade-off between risk and expected revenue, according to his or her preferences. To achieve this goal, a chance-constrained strategy $^{26}$ was implemented, based on the substitution of equation (3) by

$$
\operatorname{Pr}\left\{P_{W P i}+P_{W G i} \leq P_{W i}\right\} \geq \alpha
$$

where Pr means probability.

In this case, this leads to an equivalent deterministic equation where the $1-\alpha$ quantile of the distribution of $P_{W i}$ is used:

$$
P_{W P i}+P_{W G i} \leq\left[P_{W i}\right]_{1-\alpha}
$$

In practice, this corresponds to solving the previous model for lower values of the available wind power, leading to lower economic profit but with greater robustness. Since the value of $\alpha$ to be used is highly dependent on the importance allotted to risk, it is advisable to repeat the calculations for different values of $\alpha$, save the corresponding revenue, and let the decision maker choose the preferred solution, based on his or her trade-off between risk and revenue.

For better comprehension of this concept, an example is provided for $1 \mathrm{~h}$ of the operation day, for two different market players. The first player defines $\alpha$ equal to 75\%, giving him or her a prediction for the wind power produced in that hour of 4 MW. A more conservative player would choose a more robust solution (for instance, $\alpha=95 \%$ ), with a prediction of $2 \mathrm{MW}$ for the same hour. The second player is more likely to fulfill equation (13) with only $5 \%$ chance of failing to deliver the submit bid to the market. In contrast, the first market player is more exposed to constraint risk but can obtain a higher income if the realized wind power is not lower than $4 \mathrm{MW}$.

\section{FUNCTION B: OPTIMAL SCHEDULING OF A STORAGE DEVICE OFFERING RESERVE FOR COMPENSATION OF WIND POWER DEVIATIONS IN THE DAY-AHEAD MARKET}

In many cases, coordinating wind power and storage involves using large storage plants. Under normal operating conditions, these storage plants (pumping storage stations, in the present case) buy energy from the system during low-price periods (acting as load to the system), store the energy (such as water in an upper reservoir) and sell it during high-price periods (acting as hydraulic generators). This operation constitutes the storage plant's operational cycle. This operational cycle can be performed on a daily, weekly or yearly basis. In the present demonstration case, a daily cycle is considered. However, larger horizons could be easily represented using the module. The profit from the standard operation of one storage plant is a function of the differences between the prices in the operational cycle, the efficiencies of the storage plant and the constraints in the operation (storage capacity, generation rate, etc.). Alternatively, the storage plants can be used to compensate wind farm prediction errors. Some examples of these applications can be found in Castronuovo and Peças Lopes, ${ }^{3,7}$ Anagnostopoulos and Papantonis, ${ }^{8}$ Koeppel and Korpås, ${ }^{14}$ and Matevosyan and Söder. ${ }^{4}$ In these approaches, one wind farm or one wind farm cluster sells its production to the electricity market (bidding for the main forecast power production) and is penalized for any deviation from the initial proposal. For this reason, the wind farm (or wind farm cluster) aims to compensate the deviations in production by using a storage plant as a reserve for an optimized operation. The applications cited consider the exclusive utilization of the storage plant to compensate the wind farms' forecasting errors and including the storage plant in the wind farm facilities. In the present approach, a large external storage plant is considered. Two simultaneous objectives are considered by the storage plant:

- To operate as a conventional storage station in daily and intraday markets.

- To provide a reserve for a wind farm cluster, aiming to compensate prediction errors in wind power production.

\subsection{The conventional operation of the storage plant}

Figure 2 shows a typical $24 \mathrm{~h}$ operation of a pumped storage plant.

In Figure 2, four stages can be differentiated in the storage plant's operation cycle:

(a) Pause, waiting for low-price periods: at the beginning of the cycle, the storage plant has an energy reserve defined by $E_{r}^{\text {begin }}$. The optimal operation of the storage plant may involve waiting for the lowest price of the day (generally, at low load periods) to initiate the charge of the storage reservoir.

(b) Filling up the reservoir: during low-price periods, the storage plant connects the equipment to fill up the reservoir, acting as a load on the electricity system. As shown in Castronuovo and Peças Lopes, ${ }^{3}$ optimal action for the fillingup equipment generally involves connecting it at maximum capacity during the lowest price periods, in addition to partial charges during less convenient periods.

(c) Pause, waiting for high-price periods: when the reservoir is full, or when it is not economically convenient to store more energy in the reservoir, the storage plant may wait for the most profitable periods to sell the stocked energy. 


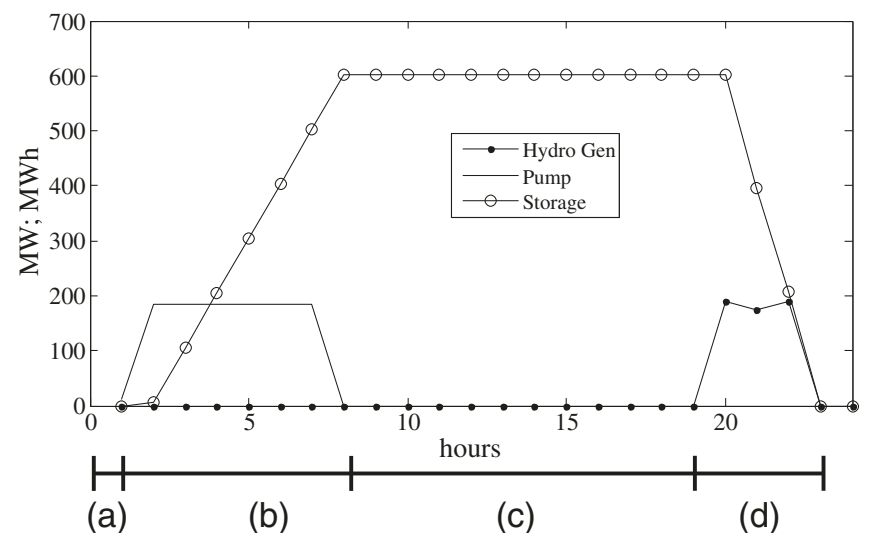

Figure 2. Example of solution of optimization problem in conventional operation.

(d) Depleting the reservoir: during high-price periods, the storage plant may deliver the stored energy to the system, depleting the reservoir. During these periods, the storage plant acts as a generator. In general, the optimal depleting action involves fully connecting the equipment during the highest price periods, ${ }^{3}$ to assure the best prices for the storage plant production. In pumping station plants, the depleting action is performed using hydraulic generation. After depleting the reservoir, the storage plant may return to stage a) to perform another operational cycle.

\subsection{Conventional + reserve optimized operation}

In the present case, the wind farm cluster bids to the electric market the main value of production $P_{W i}$, obtained from the ANEMOS.plus forecast modules, and the storage plant operates as a reserve of the wind farm cluster, compensating its forecasting errors. It was considered that the wind power production forecast during the next interval could be expressed as a mean value, enclosed in an interval defined by the minimum $\left(P_{W} m_{i}\right)$ and maximum $\left(P_{W}{ }_{i}\right)$ quantiles to be considered by the end user, according to his risk analysis.

To perform the reserve actions, the storage plant should compensate variations in the wind power production in the range of $\left[P_{W} m_{i}, P_{W} M_{i}\right]$. This reserve action of the storage plant is calculated in the present approach making minimum alterations from its conventional mode of operation (as described in the previous section).

At stage (a) (when waiting for the low-price periods), the storage plant has little energy stored at the reservoir. Therefore, it can operate as a load, absorbing the surplus of the wind power generation, if the real wind power production is greater than the expected value $P_{W i}$. The maximum value that the storage plant can absorb (filling up the reservoir) to reach the compensation objectives during each $i$ period is $\left(P_{W} M_{i}-P_{W i}\right)$. On the other hand, when wind farm production is below the predicted value $P_{W i}$, the storage plant may act as a generator, complementing the total production. To complete this action, the storage plant must guarantee sufficient stored energy to compensate the maximum deviation $\left(P_{W i}-P_{W} m_{i}\right)$, during all the $i$ intervals of the present stage. Furthermore, the stored energy remaining in the reservoir at the final interval of the operational cycle $\left(E_{r}^{\text {end }}\right)$ must guarantee the probable compensation of these lower wind farm generations in the next programming cycle. In the present case, the value of the remaining energy at the end of the simulation $\left(E_{r}^{\text {end }}\right)$ is considered the same as in the beginning of the present simulation $\left(E_{r}^{\text {begin }}\right)$.

Alternatively, at stage (c) (waiting for high-price periods), the energy reservoir has a large quantity of energy at the reservoir, allowing the storage plant to act as a generator. In this case, the storage plant can easily compensate lower wind power generation than expected, injecting up to $\left(P_{W i}-P_{W}{ }_{i}\right)$ into the system during each $i$ period. However, to compensate wind power generation that is greater than the main forecasted value, the storage plant must be able to absorb potential wind power production excesses (up to $P_{W} M_{i}-P_{W i}$ ) during each $i$ interval. Therefore, the reservoir cannot be full during any period. To assure this energy margin $\left(E^{R}\right)$ in all periods, equation (14) must be satisfied.

$$
E^{R} \leq E_{i} \leq\left(E^{M}-E^{R}\right)
$$

When the storage plant is at stage (b) (filling up the reservoir), the optimal conventional operation requires the feeding equipment to act at maximum capacity to fill the energy reservoir during the lowest-price periods. During these periods, 
the storage plant operates as a load of the electric system. Therefore, the storage plant can easily compensate wind generation that is lower than the expected value $P_{W i}$ when required, by reducing the power absorption. On the other hand, to compensate probable upper deviations in wind production, the filling-up equipment must maintain a margin to increase the load action. The maximum quantity of power to be compensated in this case is $P_{W}{ }_{i}$, during each $i$ interval. In the present approach, a continuous filling-up activity is assumed. When representing pump stations without controllable pumps, approximate or alternative approaches can be used. ${ }^{27}$ Therefore, in the combined action of the storage plant, equation (15) must be satisfied.

$$
0 \leq P_{P i} \leq\left(P_{P}^{M}-P_{W i}^{M}\right)
$$

At stage (d), the storage plant is depleting the reservoir, acting as a hydraulic generator. The optimal action (without considering wind deviations).

Figure 2 requires that generation devices act at their maximum capacity, so as to sell the stored energy during the most profitable price periods. Consequently, the storage plant can compensate probable wind productions that are higher than expected by decreasing its own production. However, as the storage plant is also required to compensate wind productions below the expected values, the plant must be able to increase the hydraulic production when required. For this reason, the storage plant must maintain a generation margin $P_{W}{ }_{i}$, to complement possible forecasting errors in the wind production. This margin may be included in the formulation, as in (16):

$$
0 \leq P_{H i} \leq\left(P_{H}^{M}-P_{W i}^{m}\right)
$$

In equations (17)-(23), the optimal conventional + reserve problem for the storage plant is formulated, simultaneously considering the objectives of improving the profit in the operational cycle and maintaining a reserve for compensating wind power forecasting errors.

$$
\begin{gathered}
\operatorname{Max} \quad \sum_{i=1}^{n}\left[p_{i} \cdot P_{H i}-c_{\text {pump }} \cdot P_{P i}-c_{\text {hydro }} \cdot P_{H i}\right] \\
\text { s.t. } \quad E_{i+1}=E_{i}+t \cdot\left[\eta_{p} \cdot P_{P i}-\frac{P_{H i}}{\eta_{H}}\right] \\
E^{R} \leq E_{i} \leq\left(E^{M}-E^{R}\right) \\
E_{1}=E_{r}^{\text {begin }} \\
E_{24}=E_{r}^{\mathrm{end}} \\
0 \leq P_{H i} \leq\left(P_{H}^{M}-P_{W i}^{m}\right) \\
P_{H i} \leq \eta_{H} \cdot \frac{E_{i}}{t} \\
0 \leq P_{P i} \leq\left(P_{P}^{M}-P_{W i}^{M}\right) \\
i=1, \ldots, n
\end{gathered}
$$

\section{FUNCTION C: MANAGEMENT OF STORAGE COUPLED WITH WIND FARMS TO MINIMIZE IMBALANCE COSTS IN ELECTRICITY MARKETS}

Power producers operating both wind farms and hydro pumping storage can participate in electricity markets as virtual power plants (VPPs) by combining them with an operational strategy that increases the controllability and predictability of the generation mix. This is an effective solution to minimize the imbalance costs resulting from differences between contracted and produced energy and consequently increase the plants' overall revenues.

The present function proposes two different methodologies to increase the operational revenues of a VPP by reducing the imbalance costs. The first is the filter operation, which compensates energy imbalances in real time without taking into account market prices. The second is a strategic operation that makes use of a loss function including wind power and market price forecasts to schedule the pumping storage operation for the coming hours. 


\subsection{Day-ahead strategy}

In the present approach, it was considered that only two wind farms bid in the day-ahead market. Wind power forecasts available at $10 \mathrm{AM}$ of the previous day are used. The VPP operator may choose to provide point forecasts or quantiles in the bid. In any case, the maximum power that can be contracted in the day-ahead market is the total wind nominal power

Pumping storage does not contribute to the definition of the day-ahead bid since its role in the present approach is to compensate imbalances in the operational phase. Furthermore, it has been considered that the VPP is a seller in the market and does not buy electricity in the market to pump water (pumping is exclusively done with generation from the wind farms).

Note that here the VPP is participating in the day-ahead market at zero price (price taker) to make sure that the bid is accepted and that this work does not consider the possibility of also participating in intraday markets.

\subsection{Operational strategy}

Before describing the two operational methods, it is important to mention that in both cases, the optimization only considers the storage as a dispatchable unit. Wind farms are assumed to be non dispatchable, although wind turbines are today able to downregulate their generation using control techniques such as pitch regulation. However, from an economic point of view, the producer is more interested in pumping excess wind energy than in wasting it by performing down regulation.

i. Filter operation

The filter operation is based on the minimization in real time of the difference between the contracted wind power and the real wind production, which corresponds exactly to the wind forecasting errors.

The mathematical equations of the optimization problem are the following:

$$
\begin{gathered}
\text { Min } \quad\left(P_{W i}+P_{H i}-P_{P i}-\hat{P}_{W i}\right) \\
\text { s.t. } \quad 0 \leq E_{i} \leq E^{M} \\
0 \leq P_{P i} \leq P_{P}^{M} \\
0 \leq P_{H i} \leq P_{H}^{M} \\
E_{i+1}=E_{i}+t \cdot\left[\eta_{p} \cdot P_{P i}-\frac{P_{H i}}{\eta_{H}}\right] \\
P_{\mathrm{VPP} i}=P_{W i}+P_{H i}-P_{P i} \\
0 \leq P_{\mathrm{VPP} i} \leq P_{W}^{\text {nom }}
\end{gathered}
$$

Note that the contracted power in the day-ahead market is exactly the forecasted wind power at each hour interval. According to the Portuguese day-ahead market rules, this forecast may have a minimum horizon of 14 h at 00:00 on each day and a maximum horizon of $38 \mathrm{~h}$ at 23:00 on each day. It can be therefore identified in the objective function (equation (25)) that the pumped storage is exclusively used to compensate the wind forecast error.

Equations (26)-(29) describe the power and energy limitations of the pumping storage station. In the present study, it has been assumed that efficiency remains constant for all charging and discharging rates. This is a simplification of real pumps and generators used in hydro stations, which typically have lower efficiencies at low operating rates. Finally, equation (31) is the technical constraint resulting from the day-ahead strategy described in 5.1. The power of the VPP $\left(\mathrm{P}_{\mathrm{VPP}}\right)$, which is the aggregation of the pumping storage station and the wind total power, cannot be negative since the VPP is not buying electricity in the market. At the same time, the power of the VPP cannot be greater than the total wind nominal power, since that is the capacity declared for participating in the market.

In Figure 3, the day-ahead strategy and the operational strategy are summarized for the case of the filter operation.

The technical constraints box corresponds to the set of equations (26)-(31) mentioned above. Once the optimization problem is solved and the different operation points obtained $\left(E, P_{P} P_{H}, P_{W}, P_{\mathrm{VPP}}\right)$, the market evaluation module is run to determine the revenues and imbalance penalties for the simulation period according to real prices in the Portuguese market. 


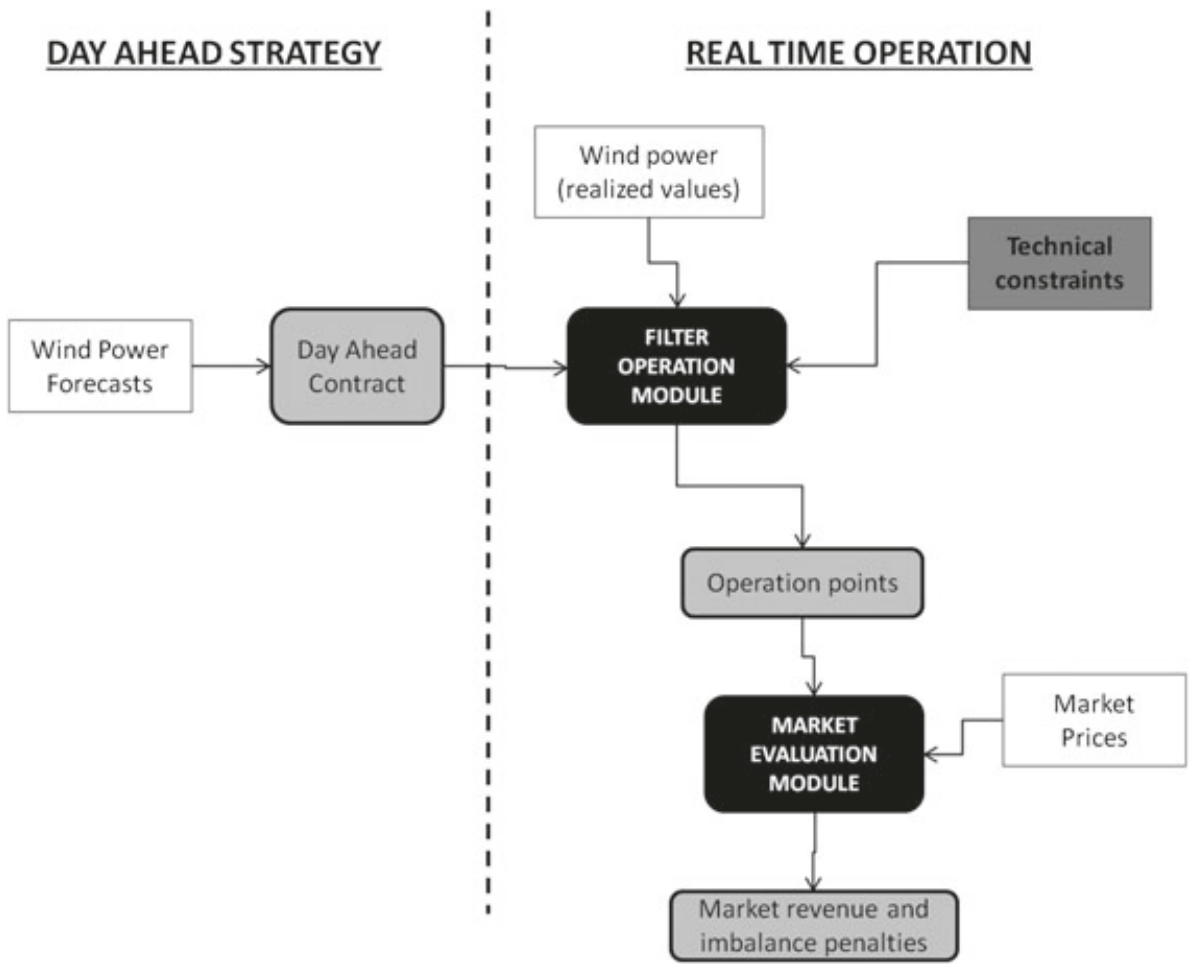

Figure 3. Simulation scheme of Function $\mathrm{C}$ with filter operation.

The calculation of revenues is based on the following equations:

$$
\begin{aligned}
p_{i}^{\mathrm{imb}} & = \begin{cases}p_{i}-p_{i}^{\text {downreg }} & \text { if } P_{\mathrm{VPP} i} \geq \hat{P}_{W i} \\
p_{i}^{\mathrm{upreg}}-p_{i} & \text { if } \quad \hat{P}_{W i} \geq P_{\mathrm{VPP} i}\end{cases} \\
\text { revenues } & =\sum_{i=1}^{i=n}\left(P_{\mathrm{VPP} i} \times p_{i}-\left|P_{\mathrm{VPP} i}-\hat{P}_{W i}\right| \times p_{i}^{\mathrm{imb}}\right)
\end{aligned}
$$

where $p_{i}^{\mathrm{imb}}$ is the imbalance price for hour $i$ in $€ / \mathrm{MWh}, p_{i}$ is the day-ahead market price at hour $i, p_{i}^{\text {downreg }}$ is the down regulation price that the plant operator must pay to the Transmission System Operator (TSO) for performing down regulation in other generation units of the system when the power generated by the VPP is above the power contracted the day before, and $p_{i}^{\text {upreg }}$ is the up regulation price that the plant operator must pay to the TSO for performing up regulation in other generation units of the system when the power generated by the VPP is below the power contracted the day before.

The revenues for a period of $n$ hours are simply the difference between the incomes generated by selling the VPP power in the day-ahead market and the imbalance cost given by the power imbalance times the imbalance price. The revenues equation can also be written as

$$
\text { revenues }=\sum_{i=1}^{i=n}\left(P_{W i} \times p_{i}\right)-\underbrace{\sum_{i=1}^{i=n}\left(P_{P i}-P_{H i}\right) \times p_{i}}_{\text {storage } \cos t}-\underbrace{\sum_{i=1}^{i=n}\left|P_{\mathrm{VPP} i}-\hat{P}_{W i}\right| \times p_{i}^{\mathrm{imb}}}_{\text {imbalance } \cos t}
$$

In this equation, the second term is the storage cost, and the third is the imbalance cost as previously mentioned. The global storage cost is difficult to estimate, but it is a combination of two effects. First, the discharged global energy will be lower than the charged global energy, as a result of efficiency losses in both directions. Second, the difference in price between the charge and discharge periods could result in an indirect cost if discharges occur more frequently than charges during low-price periods. 
This revenue equation is useful for understanding that the present operational strategy will be efficient if the reduction in the imbalance cost obtained using storage is higher than the storage cost described above.

ii. Strategic operation

The strategic operation divides the operational strategy into two stages: intraday scheduling and real-time operation. The goal of introducing an intermediate stage (intraday) is to better manage the SOC by taking advantage of the periods where the VPP is not penalized in the market. As an example, if wind production exceeds the contract but the TSO does not penalize it (spot price equals the down regulation price) because the system needs reserves, it is not worth compensating the imbalance if other production excesses leading to penalties are predicted during the next few hours. It is more convenient to keep the reservoir at a lower level to pump the maximum wind production excess when penalties are expected. To do so, an optimization to schedule SOC is performed at intraday level where both market price predictions and wind power predictions are required.

In particular, four optimizations are performed for intraday scheduling using a rolling window approach as in Costa et al. ${ }^{28}$ The window has a length of $12 \mathrm{~h}$ and moves forward $6 \mathrm{~h}$ for the next optimization as shown in Figure 4 . The reason for picking $6 \mathrm{~h}$ as the increment between optimization windows is that wind power forecasts were based on meteorological data updated every $6 \mathrm{~h}$. Therefore, new updated wind forecasts could be used in each optimization. A smaller increment between optimization windows would only make sense, if the forecasts could be updated with measurement influence from the power plants in the very short time.

The optimization problem solved at the intraday scheduling stage is based on the minimization of a loss function, which is the sum of the forecasted storage cost $\mathrm{C}_{\mathrm{ESS}}$ and the forecasted imbalance cost $\mathrm{C}_{\mathrm{IMB}}$.

$$
\operatorname{Min} \sum_{i=1}^{i=12}\left(C_{\mathrm{ESS} i}+C_{\mathrm{IMB} i}\right)
$$

s.t.

$$
\begin{array}{r}
C_{\mathrm{ESS} i}=\frac{\left(P_{H i}^{*}-P_{P i}^{*}\right) \times\left(1-\eta_{P} \eta_{H}\right) \times \hat{p}_{i}}{1+\eta_{P} \eta_{H}} \\
C_{\mathrm{IMB} i}=\left(\hat{P}_{W i}^{*}-\hat{P}_{W i}+P_{H i}^{*}-P_{P i}^{*}\right) \times \hat{p}_{i}^{\text {imb }} \\
\hat{p}_{i}^{\text {imb }}= \begin{cases}\hat{p}_{i}-\hat{p}_{i}^{\text {downreg }} & \text { if } P_{\mathrm{VPP} i}^{*} \geq \hat{P}_{W i} \\
\hat{p}_{i}^{\text {upreg }}-\hat{p}_{i} & \text { if } \hat{P}_{W i} \geq P_{\mathrm{VPP} i}^{*}\end{cases}
\end{array}
$$$$
0 \leq E_{i}^{*} \leq E^{M}
$$$$
0 \leq P_{P i} \leq P_{P}^{M}
$$

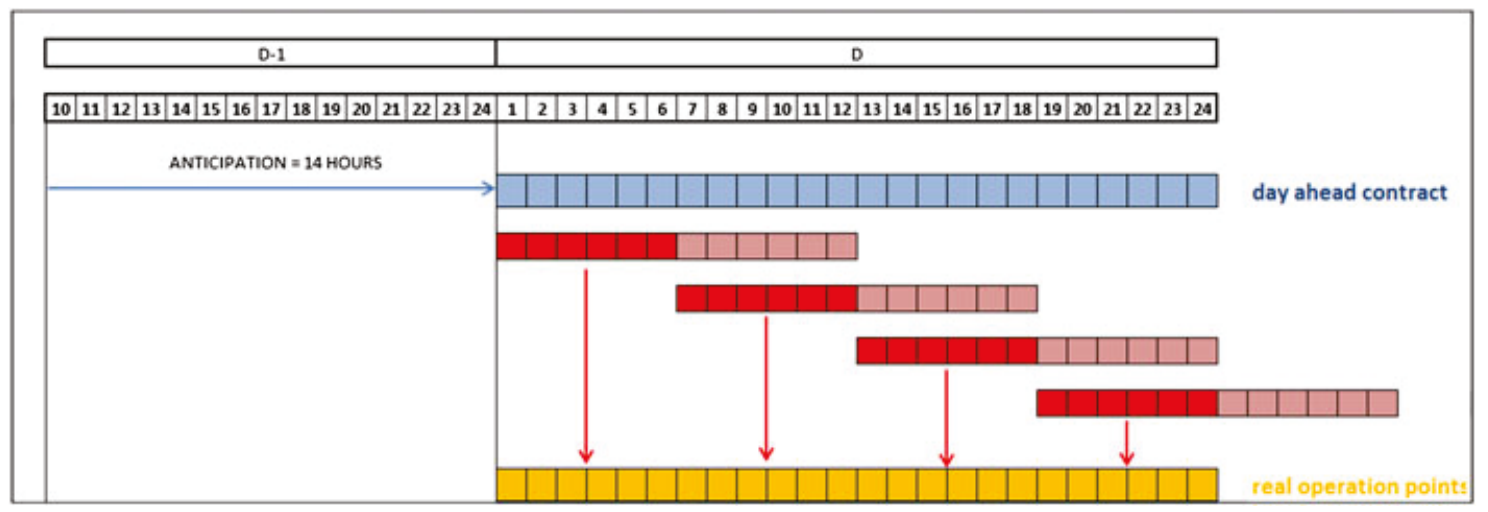

Figure 4. Intraday scheduling methodology. 


$$
\begin{gathered}
0 \leq P_{H i} \leq P_{H}^{M} \\
E_{i+1}^{*}=E_{i}^{*}+t \cdot\left[\eta_{p} \cdot P_{P i}^{*}-\frac{P_{H i}^{*}}{\eta_{H}}\right] \\
P_{\mathrm{VPP} i}^{*}=\hat{P}_{W i}^{*}+P_{H i}^{*}-P_{P i}^{*} \\
0 \leq P_{\mathrm{VPP} i}^{*} \leq P_{W}^{\mathrm{nom}}
\end{gathered}
$$

where $P_{H i}^{*}, P_{P i}^{*}$ and $P_{\mathrm{VPP} i}^{*}$ are the scheduled powers of the turbines, pumps and VPP, respectively, and $E_{i}^{*}$ is the scheduled remaining energy of the reservoir.

It is important to point out that the intraday schedule uses forecasts of both the spot price and the imbalance price (equations (36)-(38)). Also important to mention is the use of updated wind power forecasts $\left(\hat{P}_{W i}^{*}\right)$ at each of the four intraday optimizations.

Once the intraday scheduling module is completed, the first six values of $E_{i}^{*} P_{H i}^{*}$ and $P_{P i}^{*}$ in each optimization window are kept as set points for the real time operation module as shown in Figure 4. In this way, the maximum accuracy is guaranteed. The real operation module is based on following as closely as possible the set points obtained in the intraday scheduling stage. It may occur that the wind production realized is significantly different from the updated forecasts used in the intraday schedule, leading to non-optimized set points of the pumped storage. The same occurs in case of large errors for the market price forecasts. The impact of large errors of wind or price forecasts on the efficiency of the strategic operation is discussed in section 6.4.1. The mathematical equations of the real-time operation module are the following:

$$
\begin{gathered}
\operatorname{Min}\left[\left(P_{H i}-P_{P i}\right)-\left(P_{H i}^{*}-P_{P i}^{*}\right)\right] \\
\text { s.t. } \quad 0 \leq E_{i} \leq E^{M} \\
0 \leq P_{P i} \leq P_{P}^{M} \\
0 \leq P_{H i} \leq P_{H}^{M} \\
E_{i+1}=E_{i}+t \cdot\left[\eta_{p} \cdot P_{P i}-\frac{P_{H i}}{\eta_{H}}\right] \\
P_{\mathrm{VPP} i}=P_{W i}+P_{H i}-P_{P i} \\
0 \leq P_{\mathrm{VPP} i} \leq P_{W}^{\text {nom }}
\end{gathered}
$$

Once the operation points are known, the same formulas 33 and 34 are used in the market evaluation module to determine the revenues and imbalance penalties. The overall simulation scheme for the strategic operation is shown in Figure 5: simulation scheme of Function $\mathrm{C}$ with strategic operation.

\section{CASE STUDY}

\subsection{Description}

The case study considered for this problem is depicted in Figure 6 and consists in two real wind farms with a total installed capacity of around $352 \mathrm{MW}$ and a hydro station with a generation capacity of $190 \mathrm{MW}$ (92\% generation efficiency) and a pumping capacity of $184 \mathrm{MW}$ (84\% pumping efficiency). The system is located in the Iberian Peninsula. 


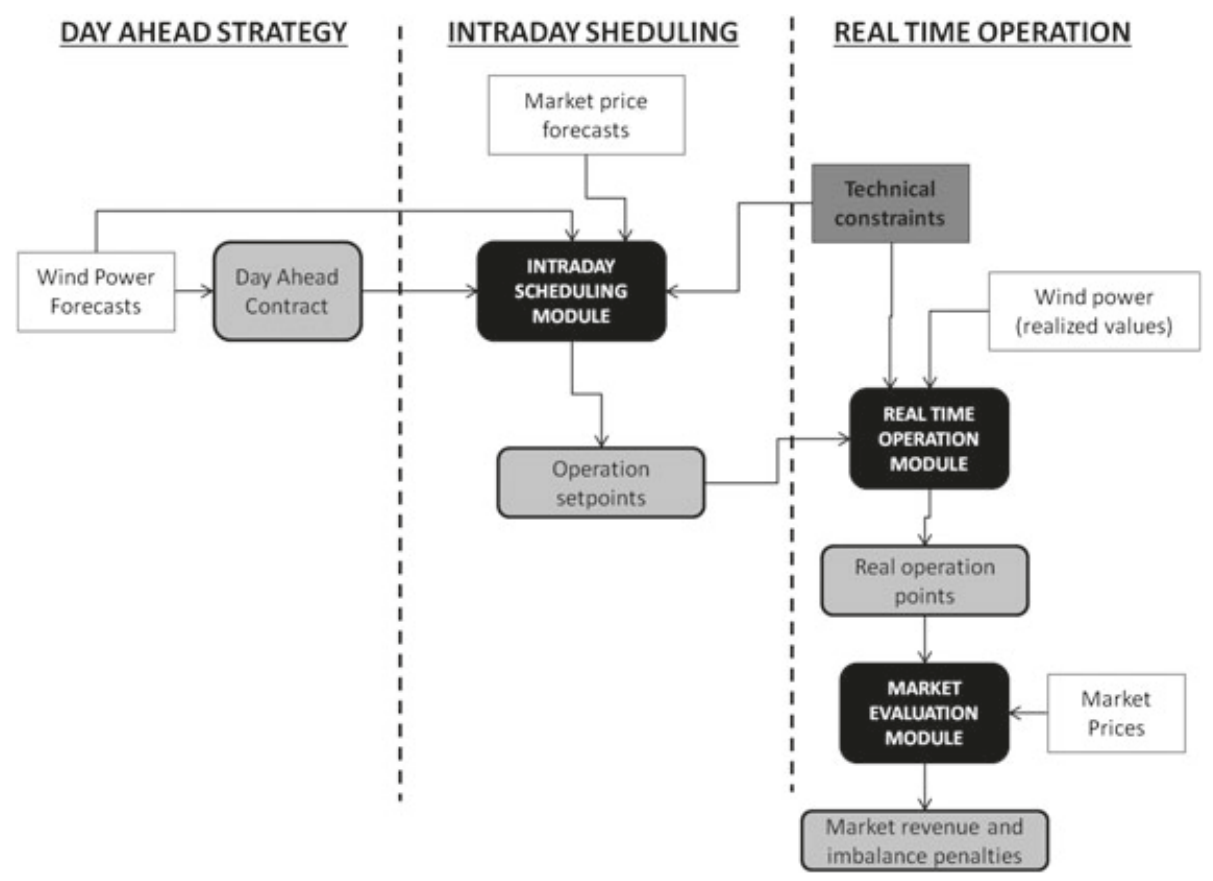

Figure 5. Simulation scheme of Function $\mathrm{C}$ with strategic operation.

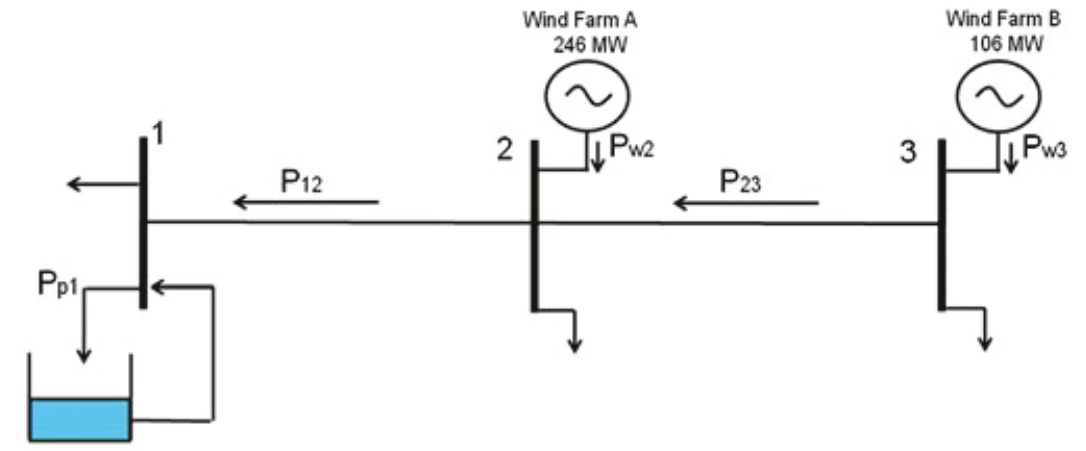

Hydro Pumping Storage Plant Generation capacity: 190 MW

Pumping capacity: $184 \mathrm{MW}$

Figure 6. Electric power system used in the case study.

\subsubsection{Operational conditions and assumptions.}

Both wind farms can supply directly into the market or partially store their active power in a hydro reservoir, using their pumping capacity. The hydro station can generate active power from the previously pumped stored wind energy. The capacity of the transmission lines connecting the wind farms to the reversible hydro plant is not considered, but the nodal power balances during each period must be maintained. No extra power flows constrain the operation of the network.

Wind power forecasts from the ANEMOS.plus platform are used for each wind farm, both point forecasts and quantiles, measuring the uncertainty associated to forecasts. To place bids in the market before closing time (10 AM), with updated information, the latest available wind power forecasts were used (i.e. dating from 6AM).

To make use of the wind energy consumed to pump water into the hydro reservoirs, the hydro station operates its reversible turbines in conventional generation mode, using the water that was previously stored to produce electric energy. The storage capacity of the real hydro station $(125,200 \mathrm{MWh})$ is very high. However, this capacity is not fully available for compensation activities. In the present case, a maximum useful storage capacity of $603 \mathrm{MWh}$ is considered. The hydro 
station also has a water inflow from the upper basin. In the simulations, $603 \mathrm{MWh}$ of water input (the average daily water inflow of the hydro station) is also considered.

Both pumping operation and maintenance costs are negligible, as well as hydro generating costs. Operationally, there is a switch time between the pumping and generation activities. However, this time gap is not considered when scheduling the hydro power station, based on the assumption that it is possible to alternately perform both pumping and generating operations during the same hour period.

The data used in this study date from 1 February 2010 to 31 July 2010. The time considered for the optimization is $24 \mathrm{~h}$ ahead. The results are presented for the whole period, giving the global revenues for the different simulations. For means of comparison, the approach is tested for the same period during 2008 and 2009 (these years present different price values).

\subsubsection{Price forecast and wind energy remuneration schemes.}

The day-ahead spot and regulation price data from the Iberian Electricity market is used. ${ }^{29}$ The price forecasts used in the simulations are obtained with a naïve approach, where the forecasted spot price for the next day is equal to the realized values of the previous day-ahead session and the regulation prices are constant and equal to the average of the previous day's regulation prices.

Two remuneration schemes for wind energy in the electricity market are considered:

1. Wind farms paid at market spot price, like the other participants in the pool.

2. Wind farms paid at the spot price plus a premium (30.98 €/MWh), and the sum spot + premium has a cap (89.86 $€ / \mathrm{MWh})$ and a floor (75.40 €/MWh).

In both models, the wind farms are penalized for any generation deviation from the scheduled production plan. The scheme (ii) reproduces the remuneration of wind farms in Spain.

\subsection{Results of Function $A$}

\subsubsection{Results with point forecasts.}

The total revenue obtained with the deterministic optimization (i.e. day-ahead optimization algorithm of section 3.1 plus the operational strategy described in section 3.2) for the five different simulations and with wind farms paid at market spot price is presented in Table I.

From Table I, it is possible to conclude that the combined wind-hydro operation leads to a $13 \%$ increase (between cases 1 and 2) in revenue with a perfect forecast and $11.3 \%$ (between cases 3 and 5) when price and wind power forecasts are used. Note that for this case study, a comparison between the revenues from cases 4 and 5 shows that an improvement in the price forecast, with more sophisticated methods (e.g. neural networks), can only increase the revenues by a maximum of $3.8 \%$ (from 9.44 to $9.8 \mathrm{M} €$ ).

Looking at Table I, one can conclude that imbalances due to forecast errors reduce the revenues in cases 4 and 5 by around $11 \%$ and $13 \%$, respectively, compared with case 2 , as they are affected by the regulation costs. It is important to stress that the use of pumping storage devices can increase the revenue by decreasing the penalization costs (a fact not taken into account in the objective function).

Finally compared with case 3 , the use of pumping storage and the operational strategy described in section 3.2 results in an increase of $15.6 \%$ for case 4 and $11.3 \%$ for case 5 .

Table II shows the total revenue obtained for the same conditions but considers the spot price plus a premium, and a cap and floor. The difference to Table I is that a premium is added to the variable spot price, which increases the revenue, and the floor (with value 75.40 €/MWh) of this spot and premium sum is much higher than the average spot price in 2010 (with value $38.1 € / \mathrm{MWh}$ ).

Adding a premium to the market price leads to higher prices and therefore greater revenues, compared with Table I. However, the way the market price calculation is formulated, with a cap and a floor, results in low variability (i.e. difference between valley and peak hours) of the wind energy price (spot plus premium), and therefore, the day-ahead optimization,

Table I. Simulation results for 2010 without price premium ('perfect' means that the realized values of wind generation were used).

\begin{tabular}{lcccc}
\hline Simulations & Price forecast & Wind power forecast & Pumping storage & Revenue [M€] \\
\hline Case 1 & Perfect & Perfect & No & 9.60 \\
Case 2 & Perfect & Perfect & Yes & 10.85 \\
Case 3 & Perfect & Forecast & No & 8.48 \\
Case 4 & Perfect & Forecast & Yes & 9.80 \\
Case 5 & Forecast & Forecast & Yes & 9.44 \\
\hline
\end{tabular}


Table II. Simulation results for 2010 with price premium, cap and floor ('perfect' means that the realized values of wind generation were used).

\begin{tabular}{lcccc}
\hline Simulations & Price forecast & Wind power forecast & Pumping storage & Revenue [M€] \\
\hline Case 1 & Perfect & Perfect & No & 27.60 \\
Case 2 & Perfect & Perfect & Yes & 27.60 \\
Case 3 & Perfect & Forecast & No & 26.48 \\
Case 4 & Perfect & Forecast & Yes & 26.48 \\
Case 5 & Forecast & Forecast & Yes & 26.48 \\
\hline
\end{tabular}

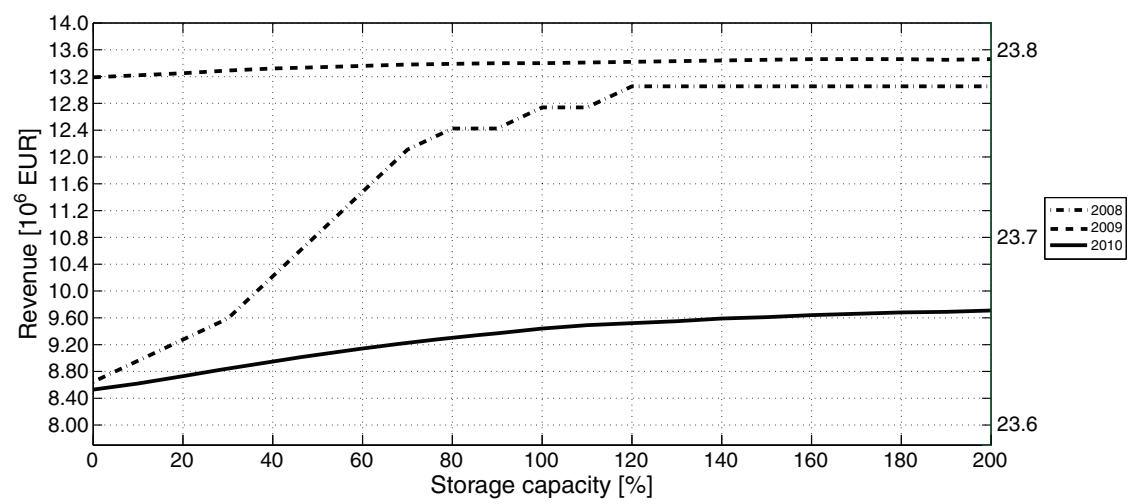

Figure 7. Revenue compared with storage capacity for 3 years. The reference storage capacity is $603 \mathrm{MWh}$. The right-hand side $y$-axis is for year 2008.

due to the low variability of the market price during the day, determines that it is not profitable to pump water in the reservoir. In fact, there is so little difference between the hours with lower prices and those with higher prices that the energy lost for efficiency reasons would be higher than the revenue in the market provided by the operation itself. Because the day-ahead optimization does not consider the use of pumping capacity to be profitable, the operational strategy relies on this decision.

The influence of the reservoir size in the wind-hydro revenue was assessed, and the results are presented in Figure 7 for a remuneration scheme without a premium. Results were also presented using the price time series of 2008 and 2009 because during these years, the market prices behaved differently (i.e. different value of the price difference between peak and valley hours) and the results therefore provide an interesting comparison.

The graph shows that an increase in storage capacity can lead to an increase in revenue up to a certain level. After that level, the increase in capacity will make no difference to the amount of power and the physical characteristics of the wind farms and hydro station considered in the problem.

The effect of the storage capacity is more visible for the year 2010. This is due to a greater difference between the hours with high and low prices during this year, i.e. ranging from $20 € / \mathrm{MWh}$ in low periods to $45 € / \mathrm{MWh}$ for peak hours. In 2009 , the prices were higher than that in 2010 but presented lower variability, ranging from $30 € / \mathrm{MWh}$ in low periods to $45 € / \mathrm{MWh}$. The year 2008 presented the highest prices, but as in 2009, price variability was low, ranging from $60 € / \mathrm{MWh}$ during low periods to $75 € / \mathrm{MWh}$ at peak hours. With these price conditions, despite higher market prices, using a pumping storage device can increase the producer's revenue but not as significantly as in the year 2010. In summary, the higher prices in 2008 and 2009 guarantee higher revenues compared with 2010, but it is the price difference between peak and valley that makes storage valuable or not, despite its storage capacity. In general, remuneration schemes removing the variability of real electricity markets do not encourage VPP strategies with wind farms and storage.

\subsubsection{Results with probabilistic forecasts.}

This subsection presents results obtained using the chance-constrained optimization (see section 3.3) for year 2010, with forecasts for all variables.

Figure 8 depicts the total revenue as a function of the solution's robustness $\alpha$ (between $60 \%$ and 95\%). The results show that the revenue drops at an increasing rate when robustness rises. Hence, the decision maker can expect bigger revenue from accepting the associated risk. In fact, one can see that decision makers who chose the solution with greater expected revenue but with a higher risk of insufficient wind power $(\alpha=60 \%)$ obtain better results that when they choose a solution 


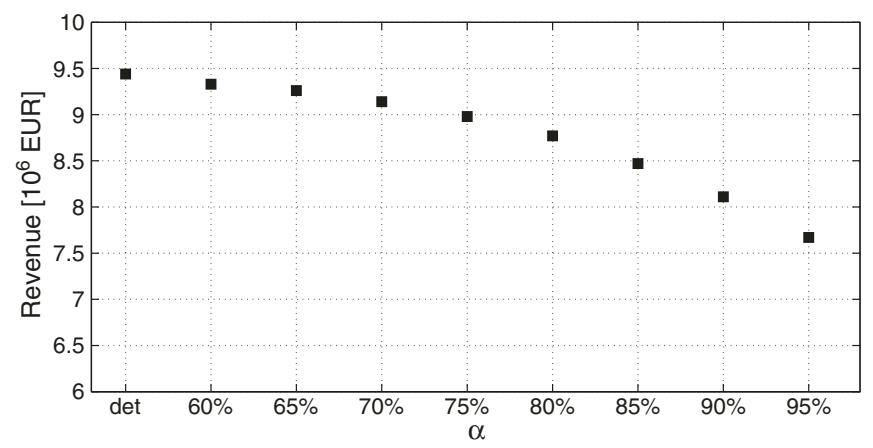

Figure 8. Results obtained with probabilistic and deterministic approaches.

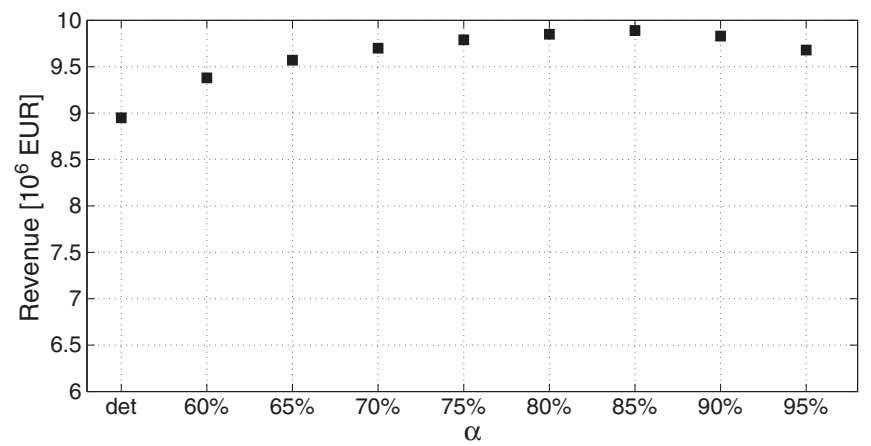

Figure 9. Probabilistic results for 2010 with swapped prices.

with higher robustness $(\alpha=95 \%)$. These results show that despite a lower value of $\alpha$, resulting in a higher risk of insufficient wind power, the possible penalizations for down imbalances (less power than predicted) are worth the risk. This is due to the regulation prices for 2010 . In this year, the average market price was $32.72 € / \mathrm{MWh}$, the average down regulation price was $9.33 € / \mathrm{MWh}$, and the average up regulation price was $3.55 € / \mathrm{MWh}$.

The regulation price for negative imbalances (i.e. realized minus forecasted value) is lower than for positive imbalances, meaning that the system penalizes the power excess in the system more than it does when there is a power deficit. Therefore, with a quantile of $95 \%$, it is likely that there will be more hours with power excess in the system, leading to lower revenues.

When the regulation prices are swapped, thus penalizing the power deficits in the system more, the situation changes. The new results are depicted in Figure 9.

In this new price structure, a decision maker that chooses the solution with higher robustness $(\alpha=95 \%)$ obtains a higher revenue than when choosing the solution with the deterministic optimization and with $\alpha=60 \%$. The solution with lower robustness is penalized by the penalization costs because of imbalances in the wind power production. The solution with $\alpha=85 \%$ turns out to be the one with highest revenue.

We should stress that for a system operator, missing power is more critical, because it is necessary to increase the generation in advance, while for power surplus, it is only necessary to increase load or decrease generation.

\subsection{Results of Function $B$}

Three operational strategies are analysed with this function:

- S1: Only Hydro Operation, following medium/large planning of the hydro resource. In line with the planning strategy, $600 \mathrm{MWh}$ of hydro energy is generated by the hydro producer during the day.

- S2: Hydro + Daily Pumping Operation. The storage capacity of the hydro plant is used to improve gains in the day-ahead market.

- S3: Hydro + Daily Pumping + Compensation of the Errors in the Wind Farm Prediction. The hydro plant increases profits by offering a portion of the storage capacity to compensate the deviations of the wind farms. To do so, a reserve 
in the operation (power and energy) is required. In the present case, the power reserve in strategy S3 is calculated using the added expected deviations of the two plants.

In strategy S1, the hydro production is performed during high-price periods. Hydro generation frequently offers production at low prices; therefore, it can be carried out during periods providing larger profits.

In strategy S2, the hydro activity is extended, making use of the plant's storage capacity to pump at the beginning of the day (and at other times with low prices). The stored energy in the intraday cycle is injected to the grid at the hours with the highest prices, increasing the production in peak periods. The activity performed in the intraday storage cycle significantly increases the profits of the hydro storage plant.

In strategy S3, the reserve in the operation increases the hydro generation period, reducing the direct profit obtained by selling the hydro production to the external system. However, the reductions in direct profit are compensated by the increased profit from compensating the wind farm deviations. The hydro plant then obtains increased profits from offering the storage capacity as a reserve to compensate wind farm deviations, derived from errors in the power forecast. It must be stressed that the combined operation of the wind farm with the hydro storage plant is profitable for both participants.

As observed in Figure 10, the requirements associated with the reserve activity result in lower energy quantities stored in the reservoir. The optimal schedule depends on the price profile and the expected level of compensation. In Table III, the profits from the three strategies are shown, considering a typical day in the period analysed (1 February 2010 to 31 July 2010) and three compensation levels of the wind farms deviations (quantiles 65, 75 and 85).

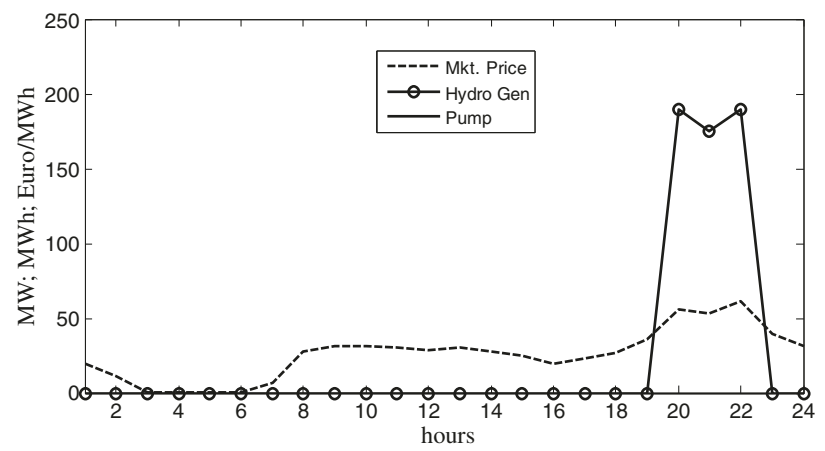

(a) S1, Only Hydro Operation

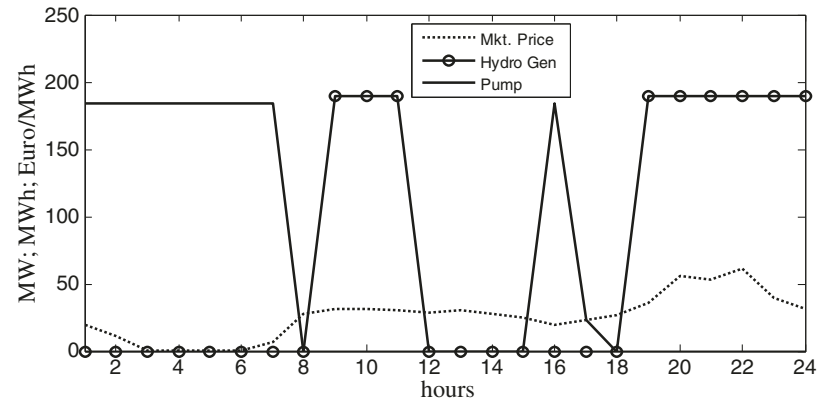

(b) S2, Hydro + Daily Pumping Operation

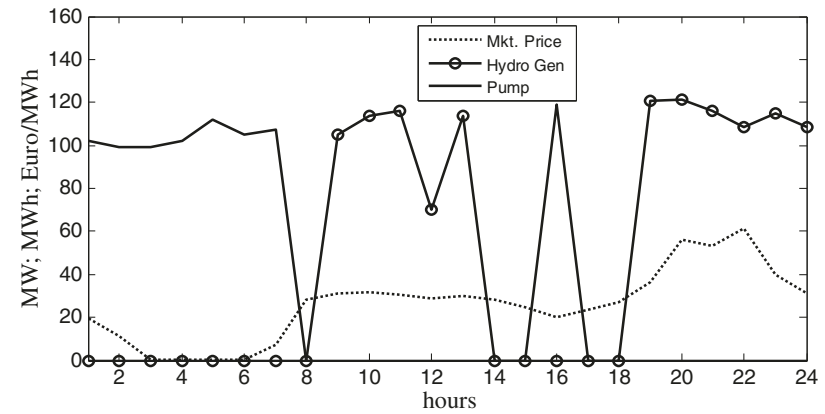

(c) S3, Hydro + Daily Pumping + Compensation of the Errors in the Wind Farm Prevision

Figure 10. Conventional + Reserve Operation of the storage plant. 
Table III. Profits in the simulations

\begin{tabular}{lccccc}
\hline \multicolumn{7}{c}{ Table lll. Profits in the simulations. } \\
& S1 & S2 & S3, quantile 65 & S3, quantile 75 & S3, quantile 85 \\
\hline Typical Day & \multirow{2}{*}{$31.58 \mathrm{M€}$} & $58.79 \mathrm{M€}$ & $60.03 \mathrm{M}$ & $60.32 \mathrm{M}$ & $59.44 \mathrm{M}$ \\
Profit (base S1) & & $86.18 \%$ & $90.09 \%$ & $91.03 \%$ & $88.23 \%$ \\
Profit (base S2) & & & $2.10 \%$ & $2.61 \%$ & $1.09 \%$ \\
\hline
\end{tabular}

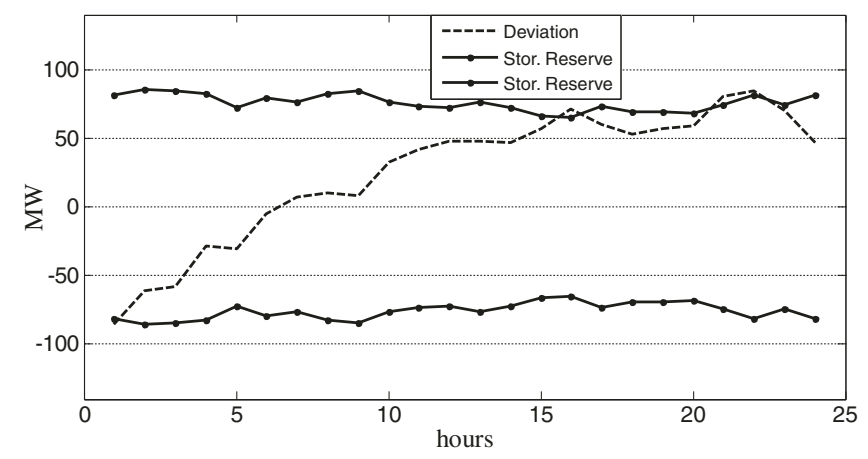

Figure 11. Compensation of wind power deviations, S3 with quantile 75.

The first line of the table shows the profits in the three operations. In strategy S3, prediction and quantiles are obtained from the forecasting tools. As can be seen in the second line of the table, the use of the storage capacities in the plant significantly increases the operation's profits $(86.18 \%$ more). Including pumping capacities in a hydro plant requires inversion costs that should be amortized by using the storage cycle. However, the compensation of production deviations in a wind farm does not require further investments in the hydro plant (if the pumping capacities are available). The reserve action of wind farms can increase the profits of the hydro plant by up to $2.61 \%$ (strategy S3), in addition to the gains obtained through optimal operation of the hydro pumping capacity (strategy S2). It must be stressed that the profits obtained by the reserve function can be impressive during periods when the prices of the reserve in the markets are high, enhancing the benefits obtained with the reserve function in the hydro plant.

In strategy S3, the increase in the number of quantile results in larger reserves in the hydro plant for compensation purposes. As an example, when considering the quantile 65 , it is expected that only $65 \%$ of the deviations in wind power production could be compensated by the action of the hydro plant. The other deviations must be compensated using the conventional (external) reserve market. There is no rule on the best quantile to use for specifying the optimal reserve in hydro plants. The optimal quantile depends on many variables: the uncertainty of wind production, the accuracy of forecasting tools, the difference between prices in the day-ahead market and the reserve market, and the risk assumed in the operation, among others. In the present simulations, the best profit is obtained using the quantile 75 .

In the Figure 11, the dotted line shows the added real deviations in wind power production at the two wind farms. This curve was calculated from the forecast of the most probable production of the plants and the real production of the farms. In the same graph, the solid lines show the reserve maintained in the hydro storage plant for compensation purposes, representing the maximum margins for the compensation action. These margins are calculated by using the quantile 75 of the forecasted wind power predictions. As observed in the figure, the real deviations lie between the compensation margins in most of the periods. During those periods, when the deviation is greater than the available compensation of the water storage plant, the wind farms must use the reserve markets of the system to balance the real production.

In the present case, the quantile 75 seems to be the best option for most of the simulated cases. The use of a large quantile can reduce the periods with greater deviations than the possible compensation. However, a larger available reserve in the hydro storage plant implies reductions in the direct profit for the hydro production. A small quantile implies the use of larger quantities of compensation by using the external reserve market, thus decreasing the profits of the wind farm. The optimal quantile to be used in each particular system must be calculated using economic simulations. The tool can calculate the best quantile to be used in the cooperation between wind farms and storage plants, depending on the specific characteristics of the system. 
Table IV. Total revenues and imbalance costs (in parenthesis).

\begin{tabular}{lccccc}
\hline Simulations & Price forecast & Wind power forecast & Pumping storage & Filter operation [M€] & Strategic operation [M€] \\
\hline Case 1 & Perfect & Perfect & No & $10.14(0)$ & $10.14(0)$ \\
Case 2 & Perfect & Perfect & Yes & $10.14(0)$ & $10.14(0)$ \\
Case 3 & Perfect & Forecast & No & $9.03(1.11)$ & $9.03(1.11)$ \\
Case 4 & Perfect & Forecast & Yes & $9.27(0.73)$ & $8.97(0.64)$ \\
Case 5 & Forecast & Forecast & Yes & $9.27(0.73)$ & $8.38(0.93)$ \\
\hline
\end{tabular}

\subsection{Results of Function C}

\subsubsection{Results with point forecasts}

In this section, the economic evaluation is performed assuming that the VPP is participating in the day-ahead market with the same market and regulation prices as the other conventional generation plants.

Table IV shows, from a comparison between case 3 (no pumped storage) and case 5, that the filter operation mode improves revenues by $2.7 \%$, while the strategic operation decreases revenues. To better understand the low results of the strategic operation, it is important to look at the imbalance cost. It can be observed that the coordination of the two wind farms and the pumped storage station reduces the imbalance cost for any of the two operation modes. When price and wind power forecasts are used (case 5), the imbalance cost reduction is $34.2 \%$ for the filter operation and $16.2 \%$ for the strategic operation. However, if perfect price forecasts are used (case 4), the strategic operation is able to further reduce the imbalance cost (42.3\%) in comparison with the filter operation (still 34.2\%). This is the first reason explaining the low results of the strategic operation: it shows the limitations of using price forecasts that are not very accurate, which is a barrier for implementation in real operational conditions.

Moreover, there is an additional problem with the strategic operation, i.e. a higher storage cost due to unfavorable trading in the market, as will be explained later. As an example, case 4, where perfect price forecasts are used, shows that the filter operation produces higher total revenues ( $€ 0.3$ million) than the strategic operation, even though the imbalance costs are lower. The reason is thus the higher storage cost resulting from the strategic operation.

To better understand the high storage cost in the strategic operation mode, a comparison was made between the reduction of imbalance cost and the storage cost (Figure 12). The storage cost in March, April and July are significantly higher than the reduction in the imbalance cost, which is definitely not advantageous for the VPP operator.

It can be concluded that there is a strong dependence between storage cost and market prices, which may cause favorable or unfavorable results in a given period depending on the imbalance cost reduction achieved.

Additional simulations were carried out to show the impact of pumped storage capacity on the revenues of the VPP. The results for different capacities are shown in Figure 13, where the reference is case 3 with no pumping storage. In general, the higher the capacity, the greater the reduction in imbalance cost and the higher the total revenues. In particular, it was observed that for a capacity 10 times larger than that studied in the present case $(603 \mathrm{MWh})$, total revenues are $8.7 \%$ greater for the filter operation (compared with $2.7 \%$ for the studied capacity) and $0.8 \%$ greater for the strategic operation mode compared with the reference case. The results prove that the impact of capacity on revenues depends on the algorithm for storage management. It is also important to point out that the revenues' increase due to capacity is not linear. For example, the revenues' increase between $100 \%$ and $200 \%$ of the studied capacity is more important than the one between $300 \%$ and $400 \%$. If the capacity was further increased, the total revenues for the filter operation would approximate more and more to 10.14 million euros which is the income generated by the two wind farms in the case of perfect wind forecasts or the income generated by the two wind farms and a pumped storage with huge capacity and $100 \%$ roundtrip efficiency.

Finally, the revenues in the case of applying premiums with a cap and a floor as defined in Section 6.1.2 are shown in the Table V. The use of premiums appears to favor the strategic operation, which provides more revenues than the filter operation for perfect price forecasts (Case 4). The reason for this is that the application of premiums with a cap and a floor results in a decrease in the market price variability, and it is during periods of low market price variability that the strategic operation is more efficient in increasing revenues, since the storage cost is now less significant compared with the imbalance cost reduction.

Concerning the filter operation, no additional revenues are obtained in the case of premiums. The total cost reduction imbalance is canceled out by the storage cost.

\subsubsection{Results with probabilistic forecasts}

The aim here is to study the impact of using probabilistic wind power forecasts (quantiles) rather than the point forecasts to define the day-ahead contract. Point forecasts, corresponding to the mean of the distribution, are optimized to minimize 


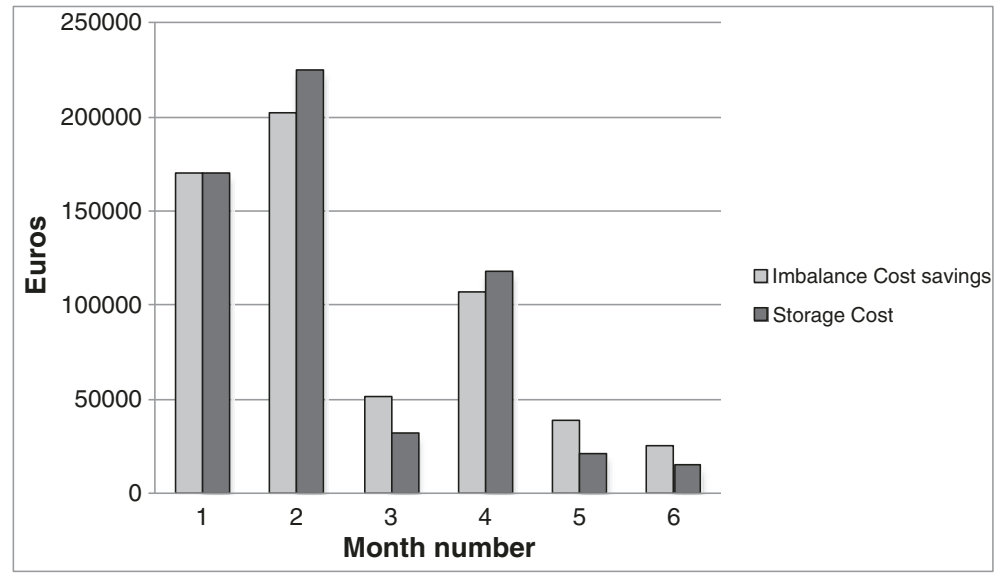

Figure 12. Storage cost and imbalance cost reduction using strategic operation.

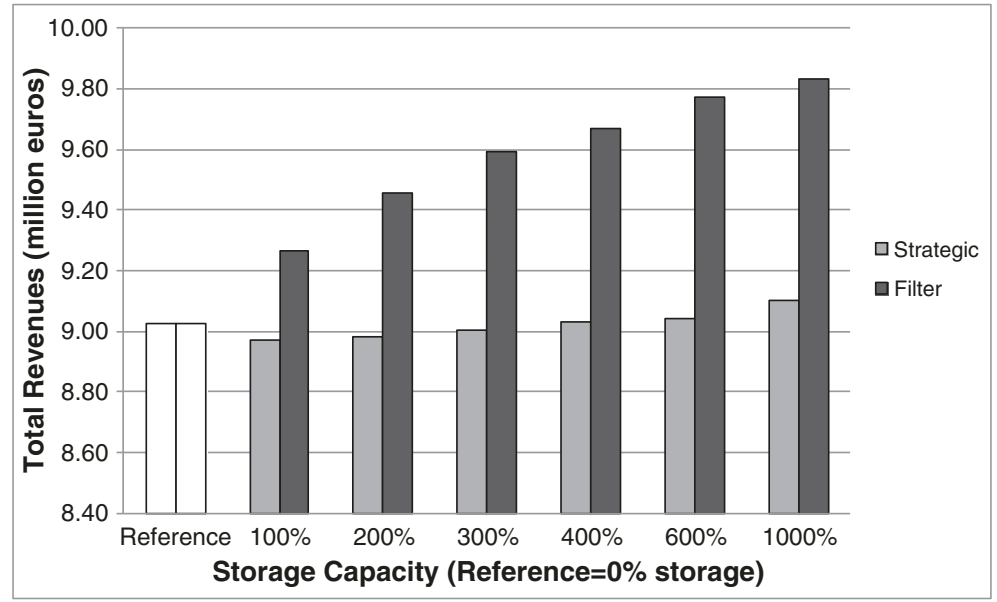

Figure 13. Total revenues versus storage capacity.

Table V. Total revenues with premiums.

\begin{tabular}{lccccc}
\hline Simulations & Price forecast & Wind power forecast & Pumping storage & Filter operation [M€] & Strategic operation [M€] \\
\hline Case 1 & Perfect & Perfect & No & 28.91 & 28.91 \\
Case 2 & Perfect & Perfect & Yes & 28.91 & 28.91 \\
Case 3 & Perfect & Forecast & No & 27.80 & 27.80 \\
Case 4 & Perfect & Forecast & Yes & 27.72 & 27.82 \\
Case 5 & Forecast & Forecast & Yes & 27.72 & 27.57 \\
\hline
\end{tabular}

forecast errors and consequently result in minimal imbalances. However, previous works in the literature study the interest of using quantiles especially in the case of asymmetric imbalance prices. The question here is to check if the use of probabilistic forecasts allows increasing revenue, at the same time compromises security through an increase of imbalances.

We consider quantiles of $60 \%, 70 \%$ and $80 \%$ that have low risk of insufficient wind, so higher robustness. Further, we consider perfect price forecasts and the filter operation mode for the storage management. The results for quantiles are summarized in Table VI, together with the point forecast results (in bold), in order to facilitate comparison. The benefit of using quantiles is not confirmed in this case, due to the particular scenario of market prices in the studied period. During the 6 months studied, positive imbalances (power surplus) were penalized in average at $9.13 € / \mathrm{MWh}$, while negative imbalances (power deficit) where penalized at 5.21 €/MWh. This means that positive imbalances were penalized $75 \%$ more than negative imbalances. Since quantiles above $60 \%$ have all more positive imbalances than the point forecast, it is not possible to compensate the higher volume of imbalances with a lower regulation price per MWh of imbalance. In fact, the imbalance 
Table VI. Imbalance energy and revenues with probabilistic forecasts versus point forecast.

\begin{tabular}{lccccc}
\hline Forecast & Imbalance energy [GWh] & Positive imbalances & Negative imbalances & Imbalance cost [M€] & Total revenues [M€] \\
\hline Point & $\mathbf{1 4 0 . 4 9}$ & $\mathbf{2 7 \%}$ & $\mathbf{7 3 \%}$ & $\mathbf{0 . 8 7}$ & $\mathbf{9 . 2 7}$ \\
$\alpha=60 \%$ & 151.96 & $48 \%$ & $52 \%$ & 9.09 & 1.05 \\
$\alpha=70 \%$ & 171.54 & $68 \%$ & $32 \%$ & 1.27 & 1.71 \\
$\alpha=80 \%$ & 209.81 & $78 \%$ & $22 \%$ & 8.43 \\
\hline
\end{tabular}

cost increases at higher rate than the volume of imbalance energy. For example, the use of $80 \%$ quantile would provide $49 \%$ more imbalance volume than the point forecast, but its imbalance cost would be $96 \%$ higher, reducing strongly the total revenues of the VPP operator.

In conclusion, the use of quantiles of high robustness in the bidding stage does not significantly improve the revenues of the VPP in the present case. The optimal forecast both in terms of revenue and imbalances is the point forecast. In another market scenario, where positive imbalances are less penalized than negative imbalances, an improvement could be observed as mentioned in Section 6.2.2. However, due to the high volatility of regulation prices and to the difficulty to predict them, the point forecasts remain the best solution, when using the filter operation for managing wind imbalances in the market.

\section{CONCLUSIONS}

A tool with three integrated functions for the optimal coordination of wind farms and storage plants is described in this article. The approach was tested to solve a realistic case study, with adequate robustness and quality in the solutions. The case study carried out intended to analyse the integration of wind farms in a market environment without a feed-in tariff. Economic gains are possible by reducing imbalance costs, which is also a way of increasing the controllability of wind power generation. As a result of the variability and uncertainty of wind power, this application may become more important as the level of wind power increases in the grids.

All the functions use the same forecasting methods and the same electricity market prices and regulations. The functions can be adapted to diverse regulatory environments and are useful to independent power producers operating both wind farms and reversible hydro power stations in their generation park, to system operators estimating the storage and reserves required in different levels of wind power integration, and to storage operators that may offer their storage capacities to wind farm operators as operating reserves.

The main goal of Function A is to store wind energy during hours with lower prices and sell it (using hydro) during hours with higher prices. The execution of the day-ahead strategy and the proposed Operational Strategy was successful, in as much as it increases the revenue of the wind farm. The results show that the use of a storage device can lead to a significant increase in revenue, up to $11 \%$ during a 6 month period in 2010 , compared with wind farms selling the energy directly to the grid without using storage. If the price difference is lower (e.g. remuneration scheme with premium, cap and floor), then the storage action is not compensatory. For instance, the revenue increase is up to $2.6 \%$ and $1.9 \%$ for 2009 and 2008, respectively, during the same months.

Regarding Function B, an adequate representation of the real operation of a hydro producer with storage abilities is obtained. The approach is able to characterize different modes of operation, including (i) hydro operation only, (ii) hydro operation and use of storage capacities, and (iii) the simultaneous use of storage capacities for increasing the profit of the hydro producer and all of the wind farms. In the latter option, the approach includes a reserve operation for deviations of production at the wind farms, which can be used by hydro plants to increase their operational revenues. The results show that the reserve action performed by the storage plant is adequate to compensate expected wind farm deviations and increases revenues by $2.6 \%$ on typical days. The approach is also suitable for use in risk analyses, resulting in the best compromise between economic risk and profit.

Concerning Function $\mathrm{C}$, the objective of the optimization is to minimize regulation costs to increase revenues. The pumped storage station is exclusively used for this purpose, instead of being also used for wind energy trading, like in approaches A and B. Two different operational strategies are studied. In the present case, only the filter operation mode resulted in an increase of wind farm revenues. By mitigating energy imbalances in real time, an increase of around $3 \%$ was achieved. This increase could be higher if further storage capacity were dedicated for imbalance management (around $9 \%$ with a storage capacity 10 times larger) or in different market conditions. On the contrary, the use of probabilistic forecasts in the bidding stage of the filter operation does not generate more revenue than that when using point forecasts, and when they do, very good prediction of regulation prices are required. Concerning the strategic operation of storage where intraday updates are made, it did not show successful results in the real case studied due to the high uncertainty present in the optimization from both wind and price forecasts. This type of operation may only be feasible in real world when short-term (intraday) wind power forecasts of high accuracy are available together with accurate price forecasts. A parametric study 
considering different levels of forecast accuracy to assess the performance of strategic storage operation is an interesting perspective for future research work.

Finally, it was proven that probabilistic forecasts of wind power such as quantiles may allow the producer (decision maker) to improve his income by minimizing the economic risk associated to wind power forecast uncertainty. In the present case study, it was demonstrated that with swapped regulation prices, the operational strategies of approach A would generate significantly more revenues using a low quantile $(15 \%)$ than the point forecast. The same tendency was observed in approaches B and C.

The three approaches taken here proved to be adequate for use in real systems. Moreover, they showed that (i) the significant inclusion of wind farms in the systems can be easily carried out with adequate operation procedures, (ii) the inclusion of wind power requires re-adapting the capacity of current equipment to innovative functions, (iii) economic profits can be obtained from a cooperation between wind farms and storage devices and (iv) optimal operation procedures can be different for the various agents used in the system, but they must be coordinated for the power system to operate efficiently.

\section{ACKNOWLEDGEMENTS}

This work was performed in the framework of project ANEMOS.plus (contract no 038692) funded in part by the European Commission under the 6th RTD Framework Program.

The author Ricardo Bessa acknowledges Fundação para a Ciência e a Tecnologia (FCT) for PhD Scholarship SFRH/BD/33738/2009. The author Jesus Lugaro acknowledges Fundación Caja Madrid for Postgraduate Scholarship 'Engineering-2010'. The authors Edgardo Castronuovo and Julio Usaola acknowledge the Ministry of Science and Technology of Spain (Projects IT2009-0063 and ENE2010-16074).

\section{REFERENCES}

1. Ortega-Vasquez MA, Kirschen DS. Estimating the spinning reserve requirements in systems with significant wind power generation penetration. IEEE Transactions on Power Systems 2009; 24: 114-124.

2. Matos MA, Bessa R. Setting the operating reserve using probabilistic wind power forecasts. IEEE Transactions on Power Systems 2011; 26: 594-603.

3. Castronuovo ED, Peças Lopes JA. On the optimization of the daily operation of a wind-hydro power plant. IEEE Transactions on Power Systems 2004; 19: 1599-1606.

4. Matevosyan J, Söder L. Short-term hydropower planning coordinated with wind power in areas with congestion problems. Wind Energy 2007; 10: 195-208.

5. Matevosyan J, Olsson M, Söder L. Hydropower planning coordinated with wind power in areas with congestion problems for trading on the spot and the regulating market. Electric Power Systems Research 2009; 79(1): 39-48.

6. Garcia-Gonazalez J, de la Muela RMR, Santos LM, Gonzalez AM. Stochastic joint optimization of wind generation and pumped-storage units in an electricity market, power systems. IEEE Transactions 2008; 23: 460-468.

7. Castronuovo ED, Peças Lopes JA. Optimal operation and hydro storage sizing of a wind-hydro power plant. International Journal of Electrical Power and Energy Systems 2004; 26: 771-778.

8. Anagnostopoulos JS, Papantonis DE. Pumping station design for a pumped-storage wind-hydro power plant. Energy Conversion and Management 2007; 48: 3009-3017.

9. Abbey C, Joos G. A stochastic optimization approach to rating of energy storage systems in wind-diesel isolated grids, power systems. IEEE Transactions 2009; 24: 418-426.

10. Brown PD, Peças Lopes JA, Matos MA. Optimization of pumped storage capacity in an isolated power system with large renewable penetration, power systems. IEEE Transactions 2008; 23: 523-531.

11. Kockl B, Stricker P, Koeppel G. On the properties of stochastic power sources in combination with local energy storage. Proceedings of CIGRÉ Symposium on Power Systems with Dispersed Generation, Athens, 2005.

12. Vieira F, Ramos HM. Hybrid solution and pump-storage optimization in water supply system efficiency: a case study. Energy Policy 2008; 36: 4142-4148.

13. Korpaas M, Holen AT, Hildrum R. Operation and sizing of energy storage for wind power plants in a market system. International Journal of Electrical Power and Energy Systems 2003; 25: 599-606.

14. Koeppel G, Korpås M. Increasing the network in-feed accuracy of wind turbines with energy storage devices. Sixth Word Energy System Conference, Torino, Italy, 2006; 365-370.

15. Bathurst GN, Strback G. Value of combining energy storage and wind in short-term energy and balancing markets. Electric Power Systems Research 2003; 67: 1-8. 
16. Martínez-Crespo J, Angarita JL, Castronuovo ED, Amaris H, Usaola García J. Approachs for the effective integration of large amounts of wind energy in the system. In Optimization Advances in Electric Power Systems. Nova Science Publishers, Inc.: New York, USA; 2008.

17. Angarita JL, Usaola J, Martinez-Crespo J. Combined hydro-wind generation bids in a pool-based electricity market. Electric Power System Research 2009; 7: 1038-1046.

18. Kariniotakis G, Lugaro J, Bessa RJ, Matos MA, Usaola J, Castronuovo ED, Pinson P, Waldl H-P, Meibom P, Focken U, Nielsen TS, Dimeas A. Proceedings of workshop: towards smart integration of wind generation. Deliverable 6.4 of the EU project ANEMOS.plus, Paris, France, 29 June 2011. Available: http://www.anemos-plus.eu/images/pubs/ workshop/aplus.deliverable_d6.4.workshop_29062011_parta.pdf (accessed March 2012).

19. Waldl H-P, Dierich F, Kariniotakis G, Bocquet A, Virlot S. The ANEMOS wind power forecasting platform. Proceedings of the European Wind Energy Conference 2006, Athens, Greece, 2006.

20. Giebel G, Brownsword R, Kariniotakis G, Denhard M, Draxl C. The state-of-the-art in short-term prediction of wind power, a literature overview, 2nd Edition, Deliverable D1.2 of the ANEMOS.plus Project, January 2011.

21. Pinson P, Nielsen HAa, Madsen H, Lange M, Kariniotakis G. Methods for the estimation of the uncertainty of wind power forecasts, ANEMOS project deliverable report D3. 1b, Informatics and Mathematical Modeling, Technical University of Denmark, 2007.

22. Nielsen HA, Madsen H, Nielsen TS. Using quantile regression to extend an existing wind power forecasting system with probabilistic forecasts. Wind Energy 2006; 9: 95-108.

23. Pinson P, Kariniotakis G. On-line assessment of prediction risk for wind power production forecasts. Wind Energy 2004; 7: 119-132.

24. Juban J, Fugon L, Kariniotakis G. Probabilistic short-term wind power forecasting based on kernel density estimators. Proceedings of the European Wind Energy Conference EWEC'07, Milan, Italy, 2007.

25. Pinson P, Papaefthymiou G, Klockl B, Nielsen HAa, Madsen H. From probabilistic forecasts to statistical scenarios of short-term wind power production. Wind Energy 2008; 12: 51-62.

26. Charnes A, Cooper WW. Deterministic equivalents for optimizing and satisficing under chance constraints. Operations Research 1963; 11: 18-39.

27. Castronuovo ED, Peças Lopes JA. Improving wind farm output control through hydro storage. Proceedings of the MedPower 2004 (4th Mediterranean Conference on Power Generation, Transmission and Distribution), Lemesos, Cyprus; 2004.

28. Costa LM, Bourry F, Kariniotakis GN. Risk based strategies for wind/pumped hydro coordination under electricity market, IEEE Power Tech Conference, Bucharest, 2009.

29. Available from: www.esios.ree.es (accessed on March 2012). 